\title{
Chronic Benzodiazepine Administration Potentiates High Voltage-Activated Calcium Currents in Hippocampal CA1 Neurons
}

\author{
Kun Xiang, Damien E. Earl, Kathleen M. Davis, David R. Giovannucci, \\ L. John Greenfield, Jr., and Elizabeth I. Tietz
}

Departments of Physiology and Pharmacology (K.X., D.E.E., K.M.D., L.J.G., E.I.T.), Neurosciences (D.R.G.), Neurology (L.J.G.), and Cellular and Molecular Neurobiology Program (K.X., D.E.E., K.M.D.), University of Toledo College of Medicine, Toledo, Ohio

Received August 6, 2008; accepted September 22, 2008

\begin{abstract}
Signs of physical dependence as a consequence of long-term drug use and a moderate abuse liability limit benzodiazepine clinical usefulness. Growing evidence suggests a role for voltage-gated calcium channel (VGCC) regulation in mediating a range of chronic drug effects from drug withdrawal phenomena to dependence on a variety of drugs of abuse. High voltageactivated (HVA) calcium currents were measured in whole-cell recordings from acutely isolated hippocampal CA1 neurons after a 1-week flurazepam (FZP) treatment that results in withdrawal-anxiety. An $\sim 1.8$-fold increase in $\mathrm{Ca}^{2+}$ current density was detected immediately after and up to 2 days but not 3 or 4 days after drug withdrawal. Current density was unchanged after acute desalkyl-FZP treatment. A significant negative shift of the half-maximal potential of activation of HVA currents was also observed but steady-state inactivation remained unchanged. FZP and diazepam showed use- and concentration-
\end{abstract}

dependent inhibition of $\mathrm{Ca}^{2+}$ currents in hippocampal cultured cells following depolarizing trains $\left(\mathrm{FZP}, \mathrm{IC}_{50}=1.8 \mu \mathrm{M}\right.$; diazepam, $\left.I_{50}=36 \mu \mathrm{M}\right)$, pointing to an additional mechanism by which benzodiazepines modulate HVA $\mathrm{Ca}^{2+}$ channels. Systemic preinjection of nimodipine $(10 \mathrm{mg} / \mathrm{kg})$, an L-type (L)VGCC antagonist, prevented the benzodiazepine-induced increase in $\alpha$-amino-3-hydroxy-5-methylisoxasole-4-propionic acid receptor (AMPAR)-mediated miniature excitatory postsynaptic current in CA1 neurons 2 days after FZP withdrawal, suggesting that AMPAR potentiation, previously linked to withdrawal-anxiety may require enhanced L-VGCC-mediated $\mathrm{Ca}^{2+}$ influx. Taken together with prior work, these findings suggest that enhanced $\mathrm{Ca}^{2+}$ entry through $\mathrm{HVA} \mathrm{Ca}^{2+}$ channels may contribute to hippocampal AMPAR plasticity and serve as a potential mechanism underlying benzodiazepine physical dependence.
Benzodiazepines, a group of positive allosteric modulators of $\mathrm{GABA}_{\mathrm{A}}$ receptors, are widely prescribed for the treatment of anxiety, insomnia, and seizure disorders. However, widespread legitimate prescription of benzodiazepines increases the proportion of patients who develop dependence. Reducing

This work was supported by Department of Health and Human Services Grants R01-DA-04075 and R01-DA-18342 from the National Institute on Drug Abuse (to E.I.T.) and predoctoral fellowships from the University of Toledo College of Medicine Biomedical Sciences Graduate Program (to K.X., D.E.E., and K.M.D.).

Article, publication date, and citation information can be found at http://jpet.aspetjournals.org.

doi:10.1124/jpet.108.144444. the dose or abrupt discontinuation of treatment may result in withdrawal symptoms, such as anxiety, agitation, sleep disturbances, and seizures or delirium after high-dose use (Griffiths and Johnson, 2005). Although it is controversial whether physical dependence can reinforce self-administration, leading to benzodiazepine dependence or addiction (Griffiths and Weerts, 1997), understanding the neuronal mechanisms underlying the consequences of long-term drug treatment may improve the clinical usefulness of benzodiazepines.

Prolonged exposure to $\mathrm{GABA}_{\mathrm{A}}$ receptor-positive allosteric modulators, including ethanol and barbiturates, as well as

ABBREVIATIONS: HVA, high voltage-activated; DHP, dihydropyridine; L-VGCC, L-type voltage-gated calcium channel; AMPAR, $\alpha$-amino-3hydroxy-5-methylisoxazole-4-propionic acid receptor; DZP, diazepam; FZP, flurazepam; mEPSC, miniature excitatory postsynaptic current; BZ, benzodiazepine; PIPES, 1,4-piperazinediethanesulfonic acid; ACSF, artificial cerebral spinal fluid; $V_{\mathrm{h}}$, half-maximal activation; HBBS, Hanks' balanced salt solution; 4-AP, 4-aminopyridine; TEA, tetraethylammonium; DIV, days in vitro; TTX, tetrodotoxin; CGP-35348, (3 aminopropyl)(diethoxymethyl) phosphinic acid; QX-314, lidocaine $N$-ethyl bromide quaternary salt; ANOVA, analysis of variance; CON, control; I-V, currentvoltage; PN200-110, \pm isopropyl-4-(2,1,3-benzoxadiazol-4-yl)-1,4-dihydro-2,6-dimethyl-5-methoxy-carbonylpyridine-3-carboxylate; $V_{H}$, membrane holding potential. 
other drugs of abuse has been reported to enhance high voltage-activated calcium channels (HVAs), predominantly L-type voltage-gated calcium channel (L-VGCC) expression (Walter and Messing, 1999; Katsura et al., 2002, 2005, 2007; Rajadhyaksha and Kosofsky, 2005; Shibasaki et al., 2007). Benzodiazepine administration can similarly regulate VGCC expression. For example, $\left[{ }^{3} \mathrm{H}\right]$ diltiazem binding sites were up-regulated in mouse cortical cultures, concomitant with an increase in L-VGCC subunit expression after 3-day exposure of mouse cortical cultures to 1,4- or 1,5-benzodiazepines and in diazepam (DZP)-treated mice exhibiting withdrawal signs (Katsura et al., 2007). Moreover, benzodiazepines can directly inhibit L-VGCC-mediated $\mathrm{Ca}^{2+}$ influx and HVA currents (Taft and DeLorenzo, 1984; Gershon, 1992; Reuveny et al., 1993; Ishizawa et al., 1997), raising the possibility that chronic benzodiazepine administration in vivo can modulate VGCC function.

VGCCs have been implicated in mediating synaptic plasticity associated with dependence on a wide range of central nervous system stimulants and depressants (Whittington and Little, 1993; Pourmotabbed et al., 1998; Rabbani and Little, 1999; Katsura et al., 2002, 2005, 2007; Watson and Little, 2002; Rajadhyaksha and Kosofsky, 2005). Specifically, previous studies from our laboratory have demonstrated an enhancement of $\alpha$-amino-3-hydroxy-5-methylisoxasole-4propionic acid receptor (AMPAR) synaptic currents in hippocampal CA1 neurons (Van Sickle and Tietz, 2002; Song et al., 2007), which was associated with anxiety-like behavior in benzodiazepine-withdrawn rats (Van Sickle et al., 2004; Xiang and Tietz, 2007). Notably, acute systemic injection of the L-VGCC antagonist nimodipine, before AMPAR current enhancement, prevented both the augmentation of AMPAR currents in hippocampal CA1 neuron and anxiety-like behavior in benzodiazepine-withdrawn rats (Xiang and Tietz, 2007). These findings are consistent with other studies showing that administration of L-VGCC antagonists can interrupt withdrawal symptoms following benzodiazepine treatment (Gupta et al., 1996; El Ganouni et al., 2004; Cui et al., 2007), pointing to a role for regulation of L-VGCCs in mediating benzodiazepine dependence. However, little is known about the possible underlying mechanisms by which such adaptations may occur.

To investigate the means by which L-VGCCs could mediate benzodiazepine withdrawal phenomena, the properties of HVA $\mathrm{Ca}^{2+}$ currents were examined using whole-cell voltageclamp techniques in hippocampal CA1 pyramidal neurons isolated from rats orally administered the water-soluble benzodiazepine flurazepam (FZP) for 1 week. The temporal pattern of changes in $\mathrm{Ca}^{2+}$ current density and activation kinetics was evaluated immediately and up to 4 days after drug withdrawal and in neurons from rats acutely administered desalkyl-FZP. In addition, the direct concentration- and usedependent effect of the benzodiazepines to affect dihydropyridine (DHP) binding and HVA $\mathrm{Ca}^{2+}$ current density was evaluated in primary hippocampal culture. Finally, the ability of nimodipine preinjection to prevent the persistent enhancement AMPAR-mediated mEPSC amplitude was examined, to determine whether L-VGCCs not only initiate AMPAR current potentiation (Xiang and Tietz, 2007) but also play an additional role in maintaining current enhancement. Collectively, the findings suggest that chronic FZP administration transiently enhances L-VGCC function, which may serve to regulate intracellular calcium signaling and ultimately contribute to AMPAR plasticity and benzodiazepine withdrawal-anxiety. Modulation of VGCC function may relate to a direct interaction between benzodiazepines and HVA channels, in addition to the well known effects of the benzodiazepines at the $\mathrm{GABA}_{\mathrm{A}}$ receptor.

\section{Materials and Methods}

\section{Protocols}

Experimental protocols involving the use of vertebrate animals were approved by the University of Toledo College of Medicine (formerly the Medical University of Ohio, Toledo, $\mathrm{OH}$ ) Institutional Animal Care and Use Committee and conformed to National Institutes of Health guidelines.

\section{In Vivo Drug Treatments}

Chronic Flurazepam Administration. Oral FZP treatment of rats was as described previously (Van Sickle et al., 2004). In short, male Sprague-Dawley rats (initial age, postnatal day 22-25; Harlan, Indianapolis, IN) were offered only saccharin solution for a 2- to 4-day adaptation period. FZP dihydrochloride, $\mathrm{pH} 5.8$, was then offered in $0.02 \%$ saccharin solution for 1 week as their only source of drinking water. The concentration of FZP was adjusted daily according to each rat's body weight and fluid consumption $(100 \mathrm{mg} / \mathrm{kg} \times 3$ days followed by $150 \mathrm{mg} / \mathrm{kg} \times 4$ days). Only rats that consumed a criterion dose of an average $\geq 120 \mathrm{mg} / \mathrm{kg} /$ day were accepted for study. At the end of drug administration, saccharin water was again provided for $0,2,3$, or 4 days before hippocampal slice preparation on postnatal day 35 to 40 rats. Pair-handled, matched control rats receive saccharin water for the same length of time. Experimenters were blinded to rat treatment groups until the completion of the data analysis.

After this chronic FZP treatment, brain levels of residual FZP and its metabolites $(1.2 \mu \mathrm{M})$ when expressed in DZP equivalents $(0.6 \mu \mathrm{M})$ are similar to that of other common chronic benzodiazepine treatments (Gallager et al., 1985; Xie and Tietz, 1992). Unlike in humans, brain levels of residual FZP and its metabolites decline rapidly over the first $24 \mathrm{~h}$ after drug removal and are no longer detectable in hippocampus in 2-day FZP-withdrawn rats (Xie and Tietz, 1992).

Acute Desalkyl-FZP Administration. To determine whether changes in hippocampal slices are specific to chronic BZ treatment, an acute dose of the primary active metabolite of FZP, desalkyl-FZP, was given to another group of rats. As described previously (Van Sickle and Tietz, 2002), desalkyl-FZP (2.5 mg/kg p.o.) was administered by gavage in an emulsion of peanut oil, water, and acacia (4:2:1). Rats were euthanized 30 min later for hippocampal slice preparation. Control rats received an equivalent volume of emulsion vehicle. The single dose of desalkyl-FZP was demonstrated previously by radioreceptor assay to result in levels of benzodiazepine activity similar to that found in rat hippocampus after 1-week FZP treatment, without a concomitant effect on $\mathrm{GABA}_{\mathrm{A}}$ receptor-mediated inhibition (Xie and Tietz, 1992).

Systemic L-VGCC Antagonist Injection. Control and FZPwithdrawn rats were given a single intraperitoneal injection of nimodipine (10 mg/kg i.p.), an L-VGCC antagonist, or $2 \mathrm{ml} / \mathrm{kg}$ vehicle (0.5\% Tween 80) 1 day after ending 1-week FZP treatment and $24 \mathrm{~h}$ before hippocampal slice preparation from 2-day FZP-withdrawn rats.

\section{Tissue Preparations}

Acutely Isolated Hippocampal CA1 Pyramidal Neurons. CA1 pyramidal neurons were acutely isolated using modifications of methods described previously (Van Sickle et al., 2002). Briefly, hippocampal slices, $400 \mu \mathrm{m}$ were prepared on a Vibratome sectioning system (Ted Pella, Inc., Reading, CA) in ice-cold, pregassed $\left(95 \% \mathrm{O}_{2}\right.$, $5 \% \mathrm{CO}_{2}$ ) buffer containing $120 \mathrm{mM} \mathrm{NaCl}, 2.5 \mathrm{mM} \mathrm{KCl}, 0.1 \mathrm{mM}$ 
$\mathrm{CaCl}_{2}, 4 \mathrm{mM} \mathrm{MgCl}_{2}, 20 \mathrm{mM}$ PIPES, and $25 \mathrm{mM}$ D-glucose, $\mathrm{pH}$ 7.4. Slices were maintained at room temperature for $2 \mathrm{~h}$ and then incubated for $40 \mathrm{~min}$ at $37^{\circ} \mathrm{C}$ in the PIPES buffer containing $120 \mathrm{mM}$ $\mathrm{NaCl}, 2.5 \mathrm{mM} \mathrm{KCl}, 1.5 \mathrm{mM} \mathrm{CaCl}_{2}, 4 \mathrm{mM} \mathrm{MgCl}_{2}, 20 \mathrm{mM}$ PIPES, and $25 \mathrm{mM}$ D-glucose, $\mathrm{pH} 7.4$, containing protease XIV (Sigma-Aldrich, St. Louis, MO), 1.4 units $/ \mathrm{ml}$. Slices were then washed for $5 \mathrm{~min}$ in 20 $\mathrm{ml}$ of bovine serum albumin $(1 \mathrm{mg} / \mathrm{ml})$ solution followed by a $10-\mathrm{min}$ wash in PIPES buffer. The CA1 region was microdissected on ice, notched, and triturated using a 25-gauge Pasteur pipette and then 30 -gauge Pasteur pipette in $100 \mu \mathrm{l}$ of ice-cold PIPES. The cell suspension $(50 \mu \mathrm{l})$ was plated on each of two polylysine-coated $(2 \mathrm{mg} / \mathrm{ml}$, poly-D-lysine; $2 \mathrm{mg} / \mathrm{ml}$, poly-DL-lysine) culture dishes for 15 to $45 \mathrm{~min}$ before recording.

Hippocampal Slice Preparation. For mEPSC recording, transverse dorsal hippocampal slices $(400 \mu \mathrm{m})$ were prepared as described above, but in ice-cold, pregassed $\left(95 \% \mathrm{O}_{2}, 5 \% \mathrm{CO}_{2}\right)$ artificial cerebrospinal fluid (ACSF) containing $120 \mathrm{mM} \mathrm{NaCl}, 2.5 \mathrm{mM} \mathrm{KCl}, 0.5 \mathrm{mM}$ $\mathrm{CaCl}_{2}, 7.0 \mathrm{mM} \mathrm{MgSO}_{4}, 1.2 \mathrm{mM} \mathrm{NaH} \mathrm{PO}_{4}, 2 \mathrm{mM} \mathrm{NaHCO}, 20 \mathrm{mM}$ D-glucose, and $1.3 \mathrm{mM}$ ascorbate, $\mathrm{pH}$ 7.4. Slices were maintained at room temperature $\left(22^{\circ} \mathrm{C}\right)$ for 15 min in gassed, low-calcium, highmagnesium ACSF and then transferred to normal ACSF containing $119 \mathrm{mM} \mathrm{NaCl}, 2.5 \mathrm{mM} \mathrm{KCl}, 1.8 \mathrm{mM} \mathrm{CaCl}_{2}, 1.3 \mathrm{mM} \mathrm{MgSO}_{4} 1.25 \mathrm{mM}$ $\mathrm{NaH}_{2} \mathrm{PO}_{4}, 26 \mathrm{mM} \mathrm{NaHCO}$, and $10 \mathrm{mM}$ D-glucose, $\mathrm{pH}$ 7.4. Slices were maintained at $22^{\circ} \mathrm{C}$ for $\geq 1 \mathrm{~h}$. During recording, slices were perfused at $2.5 \mathrm{ml} / \mathrm{min}$ with gassed $\mathrm{ACSF}$ at $22^{\circ} \mathrm{C}$.

Primary Hippocampal Neuron Cell Cultures. To evaluate the concentration-dependent and use-dependent effects of the benzodiazepines on HVA channel function, FZP and DZP effects on $\mathrm{Ca}^{2+}$ currents were evaluated in hippocampal cultured cells. Briefly, hippocampal tissue was dissected from embryonic day 18 SpragueDawley rats, collected in $1 \times$ Hanks' balanced salt solution (HBSS) (Invitrogen, Carlsbad, CA), and incubated for $20 \mathrm{~min}$ in $0.25 \%$ trypsin-EDTA (Invitrogen) at $37^{\circ} \mathrm{C}$ with $5 \% \mathrm{CO}_{2}$. The trypsin solution was aspirated, and tissue was washed three times with HBSS. HBSS was replaced by medium containing modified Eagle's medium (Cellgro) with L-glutamine, $10 \%$ fetal bovine serum (Invitrogen), $6 \mathrm{mg} / \mathrm{ml}$ glucose, and $1 \times$ penicillin/streptomycin (Invitrogen), and the tissue was triturated using flame-polished Pasteur pipettes. Dissociated cells were plated onto coverslips coated with $0.2 \mathrm{mg} / \mathrm{ml}$ poly-DLornithine (Sigma-Aldrich) at a density of $3 \times 10^{6}$ cells $/ \mathrm{ml}$ medium. The mixed glial and neuronal cultures were maintained in vitro for 10 to 14 days, and electrophysiological recordings were performed on neurons with pyramidal cell morphology.

\section{Electrophysiology}

HVA $\mathrm{Ca}^{2+}$ Current Recording. HVA currents were recorded under whole-cell voltage-clamp conditions at room temperature using patch pipettes of 3- to $6-\mathrm{M} \Omega$ resistance. Neurons with a bright and smooth appearance and pyramidal shape, with at least one moderate-to-large apical dendrite, typically with numerous additional basal and apical dendrites (Song et al., 2007), were selected for recording. Presumptive interneurons, i.e., very large pyramidalshaped neurons or bipolar neurons, as well as elliptical-shaped neurons were excluded. The external solution contained $110 \mathrm{mM} \mathrm{NaCl}$, $10 \mathrm{mM}$ HEPES, $25 \mathrm{mM}$ TEA chloride, $5.4 \mathrm{mM} \mathrm{KCl}, 5 \mathrm{mM} \mathrm{CaCl}_{2}$, $5 \mathrm{mM}$ 4-AP, $1 \mathrm{mM} \mathrm{MgCl}_{2}, 25 \mathrm{mM}$ D-glucose, and $1 \mu \mathrm{M}$ tetrodotoxin (TTX), pH 7.4. The electrode solution contained $110 \mathrm{mM} \mathrm{CsF}, 25 \mathrm{mM}$ TEA chloride, $20 \mathrm{mM}$ phosphocreatine, 50 units $/ \mathrm{ml}$ phosphocreatine kinase, $10 \mathrm{mM}$ EGTA, $10 \mathrm{mM}$ HEPES, $5 \mathrm{mM} \mathrm{NaCl}, 2 \mathrm{mM} \mathrm{MgCl} \mathrm{m}_{2}, 0.5$ $\mathrm{mM} \mathrm{CaCl} 2,0.5 \mathrm{mM} \mathrm{BaCl}_{2}, 2 \mathrm{mM} \mathrm{MgATP}$, and $0.1 \mathrm{mM} \mathrm{NaGTP}, \mathrm{pH}$ 7.3. Currents were recorded with an Axoclamp 200B amplifier (Molecular Devices, Sunnyvale, CA) using a Digidata 1200B AD/DA converter and pClamp 9.2 acquisition software (Molecular Devices). After establishing the whole-cell configuration, cells were allowed to stabilize for $10 \mathrm{~min}$ before current recording protocols were initiated. Neurons were voltage-clamped at a membrane holding potential $\left(V_{\mathrm{H}}\right)=-65 \mathrm{mV}$. Peak HVA calcium currents (picoampere) were activated with a protocol modified from Sochivko et al. (2003) using
200 -ms voltage steps to voltage levels between -70 and $+40 \mathrm{mV}$ in $10-\mathrm{mV}$ increments, preceded by a 3 -s hyperpolarization prepulse to $-80 \mathrm{mV}$. The steady-state inactivation of $\mathrm{Ca}^{2+}$ currents was evaluated with a $200-\mathrm{ms}$ test pulse to $10 \mathrm{mV}$, preceded by a $1500-\mathrm{ms}$ conditioning prepulse ranging from -80 to $10 \mathrm{mV}$, in $10-\mathrm{mV}$ increments. Currents were corrected for linear, nonspecific leak currents, and capacitive transients. Series resistance was compensated (80$90 \%$ ). Current density was calculated as a function of cell membrane capacitance (picofarads), an estimate of cell size.

$\mathbf{C a}^{2+}$ Current Analysis. Whole-cell calcium currents were analyzed off-line using Clampfit 9.2 software (Molecular Devices). Current density (picoampere per picofarad) was defined as peak current amplitude divided by membrane capacitance and was plotted as a function of membrane potential (millivolts). Activation curves were constructed using individual conductance values for each cell using the equation $G=I /\left(V_{\mathrm{t}}-V_{\mathrm{r}}\right)$, where $V_{\mathrm{t}}$ is the test voltage, $V_{\mathrm{r}}$ is the cell reversal potential, and $I$ is the measured current (Sochivko et al., 2003). The current was then normalized to $G_{\max }$, the maximal conductance. Inactivation curves were constructed by normalizing peak current amplitude to the maximal amplitude. The data points for the conductance, $\mathrm{G}$ were fitted with a Boltzmann equation: $G / G_{\max }=$ $1 /\left\{1+\exp \left[\left(V-V_{h}\right) / k\right]\right\}$, where $G_{\max }$ is the maximal $\mathrm{Ca}^{2+}$ conductance, $V_{\mathrm{H}}$ is the potential where $G$ was the half-maximal $G_{\max }$ and $k$ is a factor proportional to the slope at $V_{h}$. Data points were normalized to the maximal conductance, averaged, and plotted. Inactivation curves were constructed by normalizing the current values to the largest value then fitted with the Boltzmann equation $I(V) / I_{\max }=$ $1 /\left\{1+\exp \left[\left(V-V_{h}\right) / k\right]\right\}$.

Use- and Concentration-Dependent Inhibition of $\mathrm{Ca}^{2+} \mathrm{Cur}$ rents. The use- and concentration-dependent effect of FZP and DZP on whole-cell HVA currents was assessed in 10 to 14 days in vitro (DIV) hippocampal cultured cells. A protocol modified from Reuveny et al., (1993) was used to deliver test pulses before and following a series of depolarizing trains delivered at several frequencies. After a 200-ms baseline test pulse $\left(+10 \mathrm{mV}\right.$ from $V_{\mathrm{H}}$ at $\left.-80 \mathrm{mV}\right)$, trains of eight equivalent depolarizing pulses were delivered. Trains were applied at frequencies of $1,2,3$, or $4 \mathrm{~Hz}$ followed within $10 \mathrm{~ms}$ by another test pulse. A recovery test pulse, without prior train stimulation was given at the end of the recording to exclude run-down of $\mathrm{Ca}^{2+}$ channel function or seal degradation. The intertrain interval was $>1$ min to allow complete recovery from $\mathrm{Ca}^{2+}$-dependent inactivation between trains. To study FZP effects on HVA currents, the current density associated with each test pulse was evaluated in a train or no train condition, after 5-min preincubation with $1 \mu \mathrm{M}$ FZP or vehicle in the external recording solution. $\mathrm{Ca}^{2+}$ current density was normalized and expressed as the percentage of the current evoked by the baseline test pulse. To study concentration-dependent inhibition, benzodiazepine $(0.1-100 \mu \mathrm{M})$ effects to inhibit $\mathrm{Ca}^{2+}$ current test pulses were evaluated after 5 -min preincubation in the train condition. To determine whether benzodiazepines inhibit $\mathrm{Ca}^{2+}$ current directly or through their action on $\mathrm{GABA}_{\mathrm{A}}$ receptors, the effect of the benzodiazepine antagonist flumazenil $(1 \mu \mathrm{M})$ on HVA $\mathrm{Ca}^{2+}$ current was also studied in the presence or absence of DZP. The $\mathrm{Ca}^{2+}$ current density was normalized and expressed as a percentage of current evoked in the presence of vehicle.

AMPAR-Mediated mEPSC Recording. AMPAR-mediated mEPSCs were recorded from CA1 neurons in ACSF plus $1 \mu \mathrm{M}$ TTX, $50 \mu \mathrm{M}$ picrotoxin, and $25 \mu \mathrm{M}$ CGP-35348 using whole-cell voltage-clamp techniques (Xiang and Tietz, 2007). Patch pipettes (3-6 M 2 ) were filled with internal solution containing $132.5 \mathrm{mM}$ Cs methanesulfonate, 17.5 $\mathrm{mM} \mathrm{CsCl}, 10 \mathrm{mM}$ HEPES, $0.2 \mathrm{mM}$ EGTA, $8 \mathrm{mM} \mathrm{NaCl}, 2 \mathrm{mM} \mathrm{Mg}$-ATP, $0.3 \mathrm{mM}$ Na-GTP, and $2 \mathrm{mM}$ QX-314, pH 7.2, adjusted with $\mathrm{CsOH}$. Resting membrane potential was measured immediately upon cell break-in. Neurons were voltage-clamped $\left(V_{\mathrm{H}}=-80 \mathrm{mV}\right)$ in continuous mode (continuous single electrode voltage clamp) using an Axoclamp 2A amplifier (Molecular Devices) to isolate AMPAR-receptor-mediated from $N$-methyl-D-aspartate receptor-mediated excitatory postsynaptic currents. mEPSC activity was recorded for $5 \mathrm{~min}$ and analyzed with 
MiniAnalysis software (Synaptosoft Inc., Leonia, NJ) as described previously (Xiang and Tietz, 2007).

\section{Displacement of $\left[{ }^{3} \mathrm{H}\right]$ Dihydropyridine Binding}

The effect of benzodiazepines to inhibit DHP binding to L-VGCCs in homogenates of rat brain membranes was evaluated. Whole-brain homogenates (minus cerebellum and brain stem) were prepared as described previously (Xie and Tietz, 1992), except that the P2 pellet was initially incubated for $30 \mathrm{~min}$ at $37^{\circ} \mathrm{C}$ to remove ascorbic acid, and then tissues were freeze-thawed overnight and resuspended to a final concentration of $0.5 \mathrm{mg} / \mathrm{ml}$ as determined by bicinchoninic acid assay (Pierce Chemical, Rockford, IL). The reaction, initiated by addition of $320 \mu \mathrm{l}$ of homogenate, was incubated for $90 \mathrm{~min}$ in a dimly lit room with $40 \mu \mathrm{l}$ of $2 \mathrm{nM}$ of the high-affinity DHP antagonist, $\left[{ }^{3} \mathrm{H}\right] \mathrm{PN} 200-110$ in the presence or absence of increasing concentrations of nimodipine $(10 \mathrm{pM}$ to $1 \mathrm{mM})$ or FZP or DZP ( $1 \mathrm{nM}$ to 1 $\mathrm{mM}$ ) in $50 \mathrm{mM}$ Tris-HCl buffer, $\mathrm{pH}$ 7.7, at room temperature. Nonspecific binding was determined in the presence of $10 \mu \mathrm{M}$ nitrendipine. The binding reaction was terminated by rapid vacuum filtration on number 32 glass fiber filters (Whatman Schleicher and Schuell, Keene, $\mathrm{NH}$ ), followed by $3 \times 5 \mathrm{ml}$ of ice-cold buffer washes. Filters were equilibrated overnight and counted $5 \mathrm{~min}$ in ScintiSafe $30 \%$ (Thermo Fisher Scientific, Waltham, MA).

Statistical Comparisons. Data are reported as mean \pm S.E.M. Individual comparisons of $\mathrm{Ca}^{2+}$ current characteristics between experimental groups at each withdrawal period were by two-tailed unpaired Student's $t$ test with Bonferroni's correction $(\alpha / n)$ for multiple comparisons $(n)$ (Table 1). Peak current density $\left(V_{\mathrm{H}}=0 \mathrm{mV}\right)$ across groups was analyzed by ANOVA followed by Bonferroni's multiple comparison test (Fig. 2). Comparisons of mEPSC characteristics were by ANOVA (Fig. 7; Table 2) followed by the method of Scheffé. Asterisks denote significant differences between control and FZP-treated groups $(\alpha=0.05)$. For both whole-cell recordings of HVA $\mathrm{Ca}^{2+}$ currents and benzodiazepine displacement of $\left[{ }^{3} \mathrm{H}\right] \mathrm{PN} 200-110$, binding curves were fit by nonlinear regression, where $I=I_{\min }+$ $\left(I_{\max }-I_{\min }\right) /\left(1+10^{\wedge}\left(\left(\log \mathrm{IC}_{50}-\log [\right.\right.\right.$ drug $\left.]\right) \times$ Hill slope $\left.)\right)$.

Drug Solutions. Drugs used for superfusion during whole-cell recording were dissolved at 100 times their final concentration and added to the perfusate with a syringe pump (Razel; WPI, Sarasota, FL) at a rate of 25 to $75 \mu \mathrm{l} / \mathrm{min}$ to achieve their final concentration. Nimodipine was dissolved in $0.5 \%$ Tween 80 solution and kept in a light-tight vial. All other drugs were dissolved in distilled $\mathrm{H}_{2} \mathrm{O}$. QX-314, picrotoxin, TEA chloride, 4-AP, and nimodipine were all from Sigma-Aldrich. TTX was obtained from Alamone Laboratories (Jerusalem, Israel). CGP-35348 was purchased from Tocris Bioscience (Ellisville, MO). FZP dihydrochloride was supplied by the National Institutes of Drug Abuse Supply Program (National Institutes of Drug Abuse, Bethesda, MD).

\section{Results}

HVA $\mathrm{Ca}^{2+}$ Currents in Acutely Isolated Hippocampal CA1 Pyramidal Neurons. To study $\mathrm{Ca}^{2+}$ channel function associated with FZP administration, $\mathrm{HVA} \mathrm{Ca}^{2+}$ currents were recorded in acutely isolated hippocampal CA1 pyramidal neurons from rats after different lengths of FZP (or FZP metabolite) treatment and withdrawal. To isolate calcium currents, potassium currents were blocked with TEA, 4-AP, and $\mathrm{Cs}^{+}$and sodium currents with TTX. Elicited currents were pharmacologically confirmed as predominantly L-type $\mathrm{Ca}^{2+}$ currents via inhibition with nimodipine $(10 \mu \mathrm{M})$, a selective L-VGCC antagonist (Fig. 1B). The nimodipine-resistant current is likely attributable to $\mathrm{P} / \mathrm{Q}, \mathrm{N}$, and predominantly R-type HVA currents (Catterall, 2000). Figure 1, C and $\mathrm{D}$, shows representative $\mathrm{Ca}^{2+}$ current traces elicited in

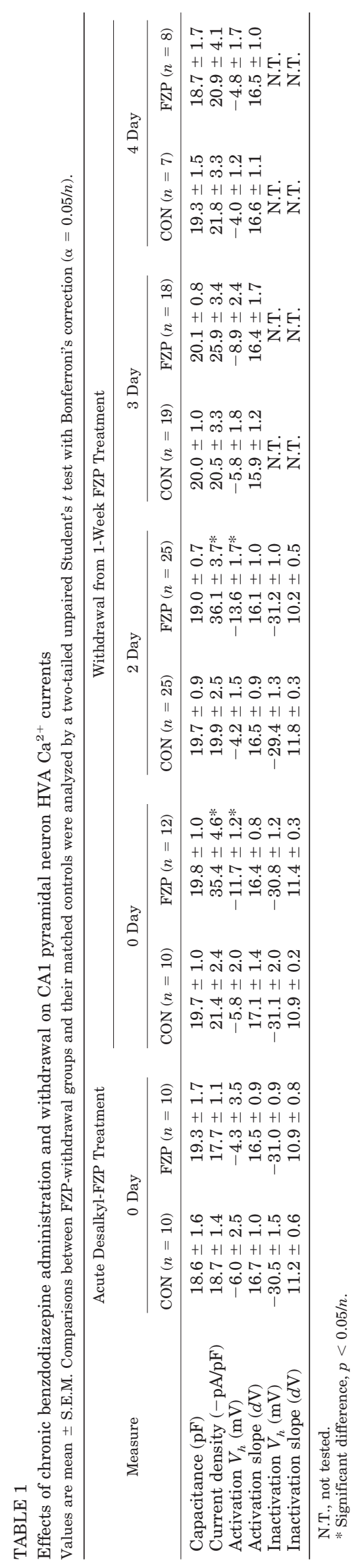


TABLE 2

Effects of systemic nimodipine on CA1 pyramidal neuron mEPSC characteristics

Values are means \pm S.E.M. Groups were compared by ANOVA followed by post hoc comparisons by the method of Scheffé; $p$ values represent post hoc comparisons between the designated injection groups.

\begin{tabular}{|c|c|c|c|c|c|}
\hline \multirow{2}{*}{ Group } & \multirow{2}{*}{ RMP } & \multicolumn{4}{|c|}{ mEPSC Characteristics } \\
\hline & & Frequency & Rise Time & Amplitude & $\tau$ \\
\hline & $m V$ & $\mathrm{~Hz}$ & $m s$ & $-p A$ & $m s$ \\
\hline CON-VEH $(n=8)$ & $-61.0 \pm 2.1$ & $0.26 \pm 0.04$ & $2.6 \pm 0.5$ & $\begin{array}{l}8.5 \pm 1.4 \\
p=0.48\end{array}$ & $\begin{array}{c}16.7 \pm 2.8 \\
p=0.70\end{array}$ \\
\hline FZP-VEH $(n=8)$ & $-61.0 \pm 1.8$ & $0.30 \pm 0.07$ & $2.8 \pm 0.3$ & $\begin{array}{c}\text { vs. CON-NIM } \\
11.1 \pm 0.9 \\
p=0.001^{*} \\
\text { vs. CON-VEH } \\
p=0.007^{*} \\
\text { vs. FZP-NIM }\end{array}$ & $\begin{array}{c}\text { vs. CON-NIM } \\
15.6 \pm 1.8 \\
p=0.90 \\
\text { vs. CON-VEH } \\
p=0.76 \\
\text { vs. FZP-NIM }\end{array}$ \\
\hline CON-NIM $(n=7)$ & $-61.4 \pm 1.7$ & $0.27 \pm 0.06$ & $2.5 \pm 0.5$ & $9.3 \pm 1.5$ & $16.3 \pm 1.5$ \\
\hline FZP-NIM $(n=7)$ & $-60.0 \pm 1.9$ & $0.27 \pm 0.05$ & $2.5 \pm 0.5$ & $\begin{array}{l}9.0 \pm 1.6 \\
p=0.99\end{array}$ & $\begin{array}{l}17.1 \pm 2.1 \\
p=0.54\end{array}$ \\
\hline ANOVA & $p>0.05$ & $p>0.05$ & $p>0.05$ & $\begin{array}{l}\text { vs. CON-NIM } \\
\quad p<0.001^{*}\end{array}$ & $\begin{array}{l}\text { vs. CON-NIM } \\
\quad p>0.05\end{array}$ \\
\hline
\end{tabular}

CON, control; NIM, intraperitoneal injection of nimodipine; RMP, resting membrane potential; VEH, intraperitoneal injection of vehicle. $* p<0.05$.

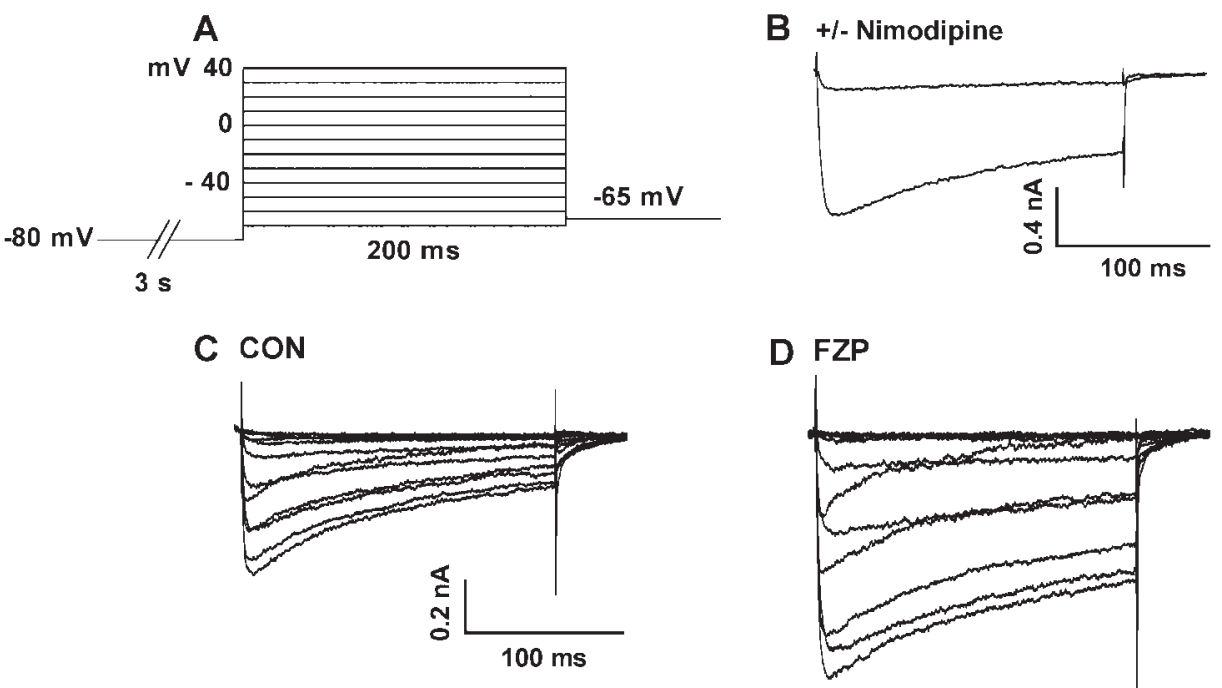

Fig. 1. Representative HVA $\mathrm{Ca}^{2+}$ current traces. Whole-cell currents were elicited from acutely isolated CA1 neurons. A, activation pulse protocol: 200-ms depolarizing voltage steps ranging from -70 to $40 \mathrm{mV}$ in $10-\mathrm{mV}$ increments were preceded by a 3 -s prepulse to $-80 \mathrm{mV}$. Membrane holding potential $\left(V_{\mathrm{H}}\right)$ was $-65 \mathrm{mV}$. B, example traces of peak $\mathrm{Ca}^{2+}$ currents evoked in a FZP withdrawn CA1 neuron at $-10 \mathrm{mV}$ in the presence and $\mathrm{ab}$ sence of $10 \mu \mathrm{M}$ nimodipine, a selective L-type VGCC antagonist. C and D, representative calcium current traces elicited in neurons isolated from a CON and a 2-day FZP-withdrawn rat.

neurons isolated from a control (CON) and a 2-day FZPwithdrawn rat (FZP), respectively.

Temporal Regulation of HVA $\mathrm{Ca}^{2+}$ Currents. The temporal pattern of changes in HVA channel function in CA1 neurons following acute treatment and after withdrawal from 1-week FZP treatment is summarized in Fig. 2 and Table 1. To demonstrate that enhanced HVA current density associated with FZP treatment was specific to protracted benzodiazepine exposure, an acute dose of the primary FZPactive metabolite, desalkyl-FZP (2.5 mg/kg p.o.), was given to one group of rats. This dose results in comparable benzodiazepine levels to that after 1-week FZP treatment (Van Sickle et al., 2004). Control rats received only the emulsion vehicle. There were no significant differences in $\mathrm{Ca}^{2+}$ current density in neurons from acute desalkyl-FZP-treated rats $(n=$ 10) in comparison with controls $(n=10)$ (Fig. 2A). The current-voltage (I-V) curves generated in neurons from acutely treated rats and their controls were superimposable (Fig. 2A), similar to that illustrated after 4-day withdrawal in Fig. 2E.

The withdrawal periods examined after 1-week FZP administration precede and extend beyond the window of enhanced AMPAR glutamatergic strength associated with anx- iety-like behavior (Van Sickle et al., 2004; Xiang and Tietz, 2007). I-V plots and peak current density in control neurons were similar to those described previously in dissociated CA1 neurons (Gorter et al., 2002) and were similar across all control groups (ANOVA, $F=2.1, \mathrm{df}=4, p=0.09$ ) (Fig. 2, A-E). There was a significant increase in $\mathrm{Ca}^{2+}$ current density in CA1 neurons isolated from rats immediately after (0-day) withdrawal from 1-week FZP treatment ( $n=12, p<$ 0.05 ; ANOVA, $F=3.8, \mathrm{df}=9, p<0.0002$ ) compared with that from matched control rats $(n=10)$ (Fig. $2 \mathrm{~B})$. The increase in $\mathrm{Ca}^{2+}$ current density was sustained up to 2 days. That is, an equivalent increase in current density was found in neurons from 2-day FZP-withdrawn rats $(n=25 ; * p<$ $0.01)$ in comparison with control neurons ( $n=25)$ (Fig. $2 \mathrm{C}$ ). $\mathrm{Ca}^{2+}$ current density was not significantly increased when examined in neurons from 3-day FZP-withdrawn rats $(n=$ 18) (Fig. 2D) compared with matched control rats $(n=19$; $p>0.05$ ). After 4-day withdrawal, when AMPAR function has returned to baseline (Van Sickle et al., 2004), there were no significant differences in $\mathrm{Ca}^{2+}$ current density in FZPwithdrawn rats $(n=8 ; p>0.05)$ in comparison with controls $(n=7)$ (Fig. 2E). The time course of changes in peak $\mathrm{Ca}^{2+}$ current density $\left(V_{\mathrm{H}}=0 \mathrm{mV}\right)$ is illustrated in Fig. $2 \mathrm{~F}$. 
A

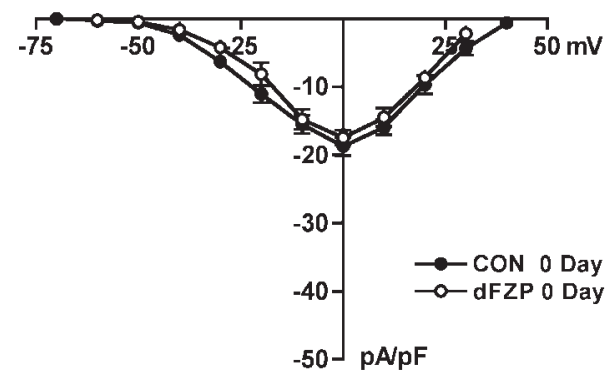

C

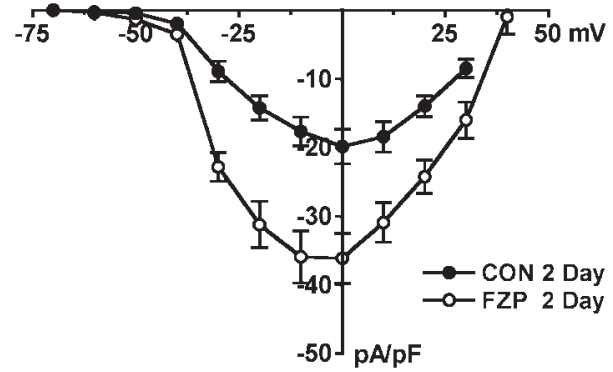

E

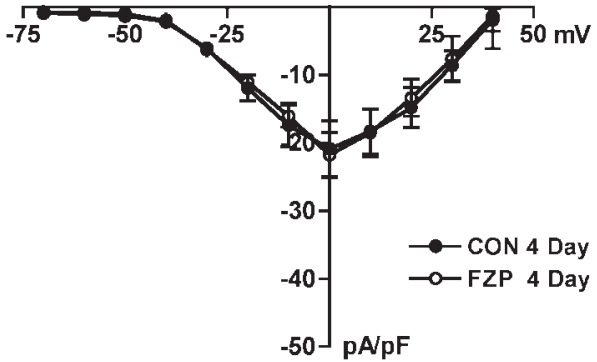

B

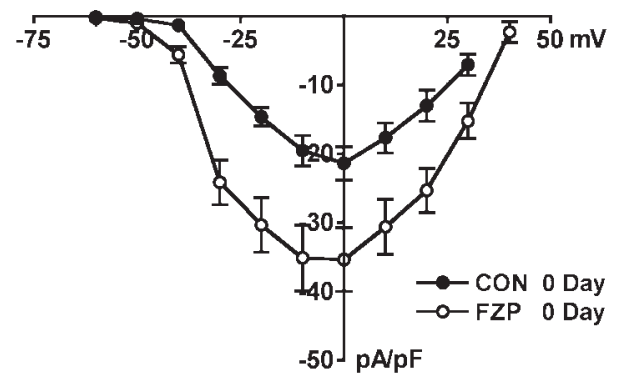

D

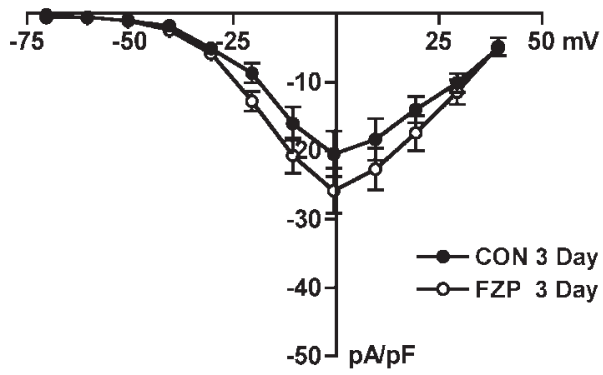

F

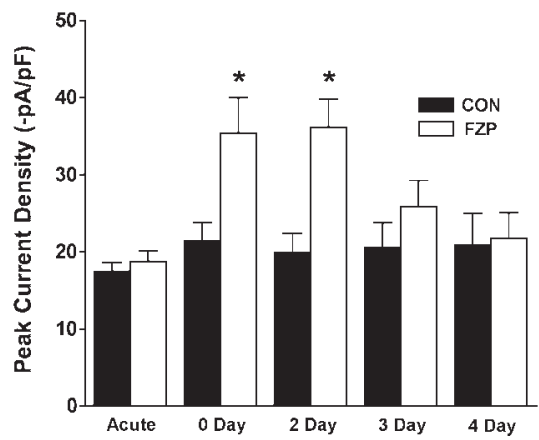

Fig. 2. I-V relationship of HVA $\mathrm{Ca}^{2+}$ currents elicited from isolated CA1 neurons. $\mathrm{Ca}^{2+}$ currents were normalized by the membrane capacitance of individual neurons and are represented as current density (picoampere per picofarad). A, for acute treatment, rats were similarly acclimated and offered saccharin water for 1 week followed by gavage $(2.5 \mathrm{mg} / \mathrm{kg}$ p.o.) with the primary FZP metabolite desalkyl-FZP, a dose that results in comparable BZ levels to that after 1-week FZP treatment. Acute desalkyl-FZP treatment had no effect on $\mathrm{Ca}^{2+}$ current density (open circles, $n=10 ; *, p<0.05$ ) compared with that from matched control rats (closed circles, $n=10$ ). $\mathrm{B}$, there was a significant increase in $\mathrm{Ca}^{2+}$ current density in $\mathrm{CA} 1$ neurons isolated from rats immediately after (0-day) withdrawal from 1-week oral FZP-treatment (open circles, $n=12 ; *, p<0.05$ ) compared with that from matched control rats (close circles, $n=10$ ). $\mathrm{C}$, a similar increase in $\mathrm{Ca}^{2+}$ current density was found in neurons from 2-day FZP-withdrawn rats

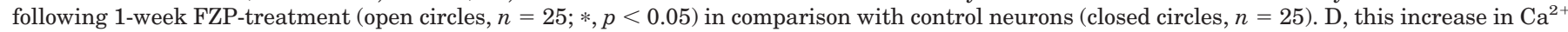
current density was no longer significant when examined in neurons from rats treated 1-week with FZP and withdrawn for 3 days (closed circles, $n=$ $9 ; p>0.05$ ) compared with matched control rats (open circles, $n=10$ ). E, there were also no significant differences in $\mathrm{Ca}^{2+}$ current density in neurons from 4-day FZP-withdrawn rats (closed circles, $n=8 ; p>0.05$ ) in comparison with matched controls (open circles, $n=7$ ). F, temporal pattern of changes in CA1 neuron HVA Ca ${ }^{2+}$ currents during acute and chronic FZP treatment and withdrawal. Peak $\mathrm{Ca}^{2+}$ current density at $V_{\mathrm{H}}=0 \mathrm{mV}$ is shown. Acute, 0 days (CON: $n=10$, closed bars; FZP: $n=10$, open bars); 0 days (CON: $n=10$, closed bars; FZP: $n=12$, open bars); 2 days (CON: $n=25$, closed bars; FZP: $n=25$, open bars); 3 days (CON: $n=10$, closed bars; FZP: $n=9$, open bars); or 4 days (CON: $n=8$, closed bars; FZP: $n=$ 7, open bars) after ending 1-week FZP treatment.

Voltage Dependence of $\mathrm{Ca}^{2+}$ Current Activation Is Altered after FZP Administration. Current amplitudes elicited by voltage steps from individual neurons were transformed to yield activation curves. Corresponding to the time course of the regulation of $\mathrm{Ca}^{2+}$ current density, there was a significant negative shift of the activation curve obtained from 0- and 2-day FZP-withdrawn rats compared with neurons from matched control rats (Fig. 3A). As shown in Table 1 , the voltages of half-maximal activation $\left(V_{h}\right)$ were significantly ( $p=0.008)$, negatively shifted (Fig. $3 \mathrm{~B}$ ) in neurons from 0 -day FZP-withdrawn rats $(n=11)$ compared with their matched controls $(n=9 ; p<0.05)$. This shift was also observed in neurons from 2-day FZP-withdrawn rats $(n=25)$ compared with their controls $(n=25 ; p<0.001)$. There were no significant differences between the slopes of the activation curves between any FZP-withdrawn group and their matched control group (Fig. 3C). There were no differences in voltage dependence of $\mathrm{Ca}^{2+}$ current activation immediately after acute desalkyl-FZP, or 3 or 4 days after 1-week FZP treatment in comparison with controls (Table 1).

Voltage Dependence of $\mathrm{Ca}^{2+}$ Current Steady-State Inactivation Remained Unchanged. Representative steadystate inactivation of $\mathrm{Ca}^{2+}$ current traces from CA1 neurons isolated from a control and a 2-day FZP-withdrawn rat are shown in Fig. 4, B and C. As shown in Fig. 4D, inactivation curves were derived by fitting the Boltzman function to $\mathrm{Ca}^{2+}$ currents elicited from individual neurons isolated from control and FZP-withdrawn rats. There were no significant shifts in the 
A
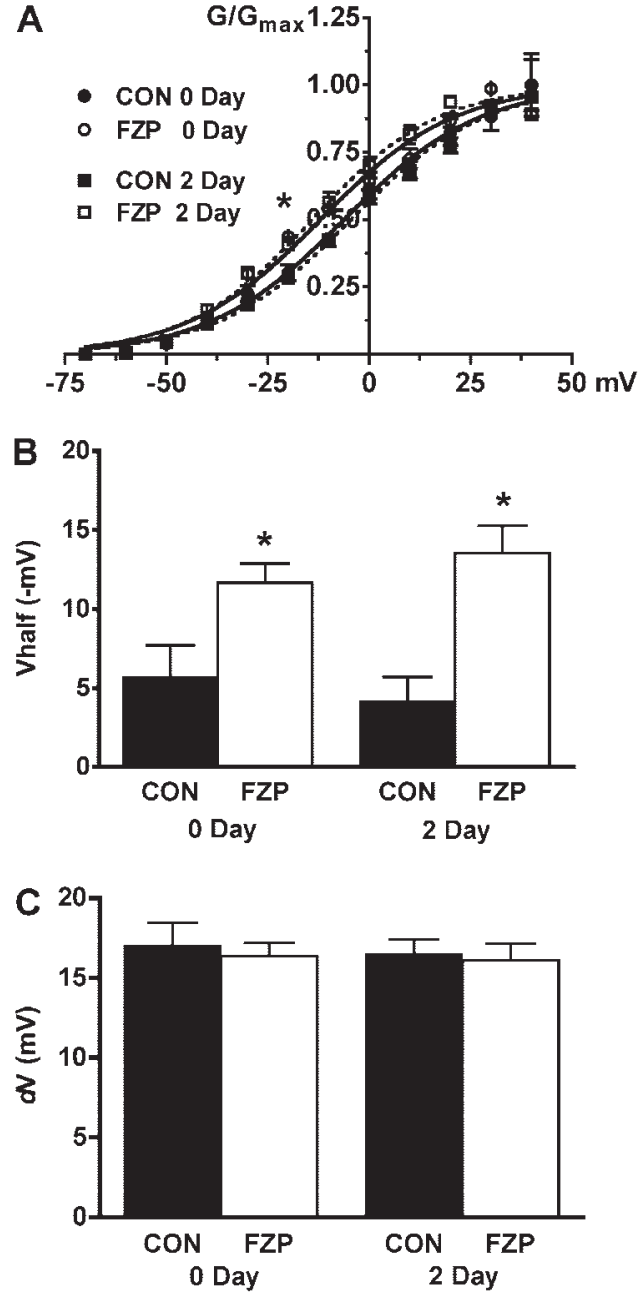

Fig. 3. Voltage dependence of $\mathrm{Ca}^{2+}$ current activation. A, current amplitudes elicited by voltage steps from individual neurons were transformed into conductance, normalized to the maximal conductance, and fitted with Boltzmann's equation. There was a significant negative shift of the activation curves derived from FZP-withdrawn rats ( 0 day, open circles; 2 day, open squares) compared with neurons from matched control rats ( 0 day, closed circles; 2 day, closed squares). B, voltages of $V_{h}$ were significantly decreased in neurons from both 0-day FZP-withdrawn rats (open bars, $n=12$ ) compared with controls (solid bars, $n=10 ; *, p<0.05$ ), as well as 2-day FZP-withdrawn rats (open bars, $n=25$ ) compared with their controls (solid bars, $n=25 ; *, p<0.05$ ). C, there was no significant difference between the slopes $(d \mathrm{~V})$ of the activation curves between any FZP-withdrawn group (open bars) and their matched control group (solid bars, $p>0.05$ ).

inactivation curves from either 0- or 2-day FZP-withdrawn neurons compared with matched control neurons (Fig. 4D). As shown in Table 1, the voltages of half-maximal inactivation $\left(V_{h}\right)$ were not significantly different from that of FZP-withdrawn rats compared with their matched control rats (Fig. 4E). There were also no significant differences in the slopes of the inactivation curves $(d \mathrm{~V})$ between the FZP-withdrawn groups and their matched control group (Fig. 4F). Because no changes in inactivation were noted in neurons from rats withdrawn at earlier time points, inactivation was not tested in neurons derived from 3- or 4-day FZP-withdrawn rats in which no other changes in HVA $\mathrm{Ca}^{2+}$ currents were observed. There was no difference in the voltage dependence of $\mathrm{Ca}^{2+}$ current steadystate inactivation immediately after acute desalkyl-FZP in comparison with their matched controls (Table 1).
Low Potency of Benzodiazepines at $\left[{ }^{3} \mathrm{H}\right]$ Dihydropyridine Binding Sites. One mechanism by which benzodiazepines might increase $\mathrm{HVA} \mathrm{Ca}^{2+}$ currents is by directly binding to and inhibiting L-VGCCs, possibly resulting in compensatory up-regulation of L-VGCC function. Such binding to L-VGCCs by benzodiazepines might be expected to disrupt the binding of conventional DHP L-VGCC antagonists. To evaluate whether FZP might directly inhibit L-VGCC function by binding to L-VGCCs, we measured, the ability of benzodiazepines to inhibit binding of the highaffinity DHP $\left[{ }^{3} \mathrm{H}\right] \mathrm{PN} 200-110$ to rat brain synaptosomes in a Tris-Cl buffer in the absence of divalent and trivalent cations (Peterson and Catterall, 1995), which enhance positive cooperativity. As illustrated in Fig. 5, FZP exhibited weak concentration-dependent inhibition of specific $\left[{ }^{3} \mathrm{H}\right]-$ PN200-110 binding (FZP IC I0 $=0.4 \mathrm{mM}$ ), whereas the prototype benzodiazepine, DZP, exhibited even lower potency $\left(\mathrm{IC}_{50}=1.3 \mathrm{mM}\right)$. A nimodipine displacement curve was used as a standard for comparison. The benzodiazepines demonstrated 40- to 130 -fold lower potency compared with nimodipine $\left(\mathrm{IC}_{50}=10.2 \mathrm{nM}\right)$

Use- and Concentration-Dependent Inhibition of HVA $\mathrm{Ca}^{2+}$ Current by FZP and DZP. It was next important to determine whether benzodiazepines can inhibit HVA $\mathrm{Ca}^{2+}$ currents and whether this occurs at physiologically relevant concentrations. The use- and concentration-dependent effects of benzodiazepines on HVA $\mathrm{Ca}^{2+}$ currents were evaluated in DIV 10 to 14 hippocampal cultured cells. FZP (1 $\mu \mathrm{M})$ had no effect on HVA $\mathrm{Ca}^{2+}$ currents in hippocampal cultured neurons in which depolarizing pulses were not applied (VEH, $83.8 \pm 3.9 \%$; FZP, $84.9 \pm 5.1 \%$; $p>0.05$ ) (Fig. 6 , $\mathrm{A}$ and $\mathrm{B})$. However, there was a slight run-down of HVA currents after repeated test pulses in the presence of vehicle. There were no differences between the benzodiazepines effect at the frequencies sampled (1-4 Hz); therefore, the inhibition data were averaged. In neurons in which consecutive depolarizing trains were applied, there was a significant inhibition of HVA $\mathrm{Ca}^{2+}$ current density by $1 \mu \mathrm{M}$ FZP compared with vehicle (VEH, $35.9 \pm 5.6 \%, n=4$; FZP, $20.3 \pm 2.4 \%, n=$ $4 ; p<0.05)$. The progressive decline in $\mathrm{HVA} \mathrm{Ca}^{2+}$ currents with repeated stimulation probably represents $\mathrm{Ca}^{2+}$-dependent inactivation of HVA currents after a train of consecutive depolarizing pulses as reported by Budde et al. (2002). The response returned to $94.7 \%$ of baseline upon recovery in the vehicle group and $67.4 \%$ in FZP group, suggesting the inhibition during depolarizing trains was not related the rundown of $\mathrm{Ca}^{2+}$ channel function or seal degradation (Fig. 6, A and $\mathrm{B}$ ).

The concentration-dependent effects of benzodiazepines on HVA $\mathrm{Ca}^{2+}$ currents were also investigated. FZP and DZP (0.1-100 $\mu \mathrm{M})$ inhibition of $\mathrm{Ca}^{2+}$ current test pulses following depolarizing trains were evaluated after 5 -min preincubation. As shown in Fig. 6C, both FZP and DZP $(0.1-100 \mu \mathrm{M})$ inhibit $\mathrm{HVA} \mathrm{Ca}^{2+}$ currents in a concentration-dependent manner. The $\mathrm{IC}_{50}$ value for FZP inhibition of $\mathrm{Ca}^{2+}$ current was $\sim 2.0 \mu \mathrm{M}\left(\log \mathrm{IC}_{50}=-5.7 \pm 0.3\right)$, with complete block of $\mathrm{Ca}^{2+}$ currents at $100 \mu \mathrm{M}$ FZP. DZP had a similar, but less potent, inhibitory effect on $\mathrm{HVA} \mathrm{Ca}^{2+}$ currents. The $\mathrm{IC}_{50}$ value for DZP inhibition was $\sim 40 \mu \mathrm{M}\left(\log \mathrm{IC}_{50}=-4.4 \pm 0.2\right)$, and $100 \mu \mathrm{M}$ DZP inhibited only $\sim 75 \%$ of the $\mathrm{Ca}^{2+}$ current. The inhibition of $\mathrm{Ca}^{2+}$ currents by the benzodiazepine antagonists was also similar in magnitude across each frequency 
A

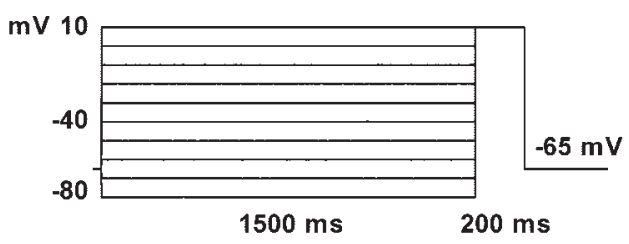

B CON

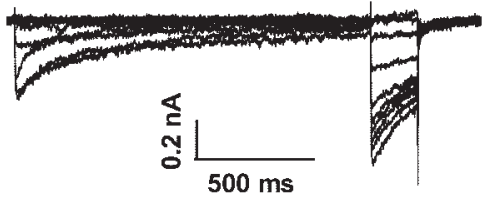

C

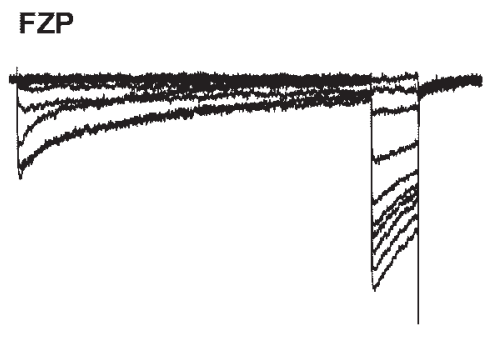

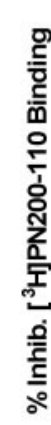

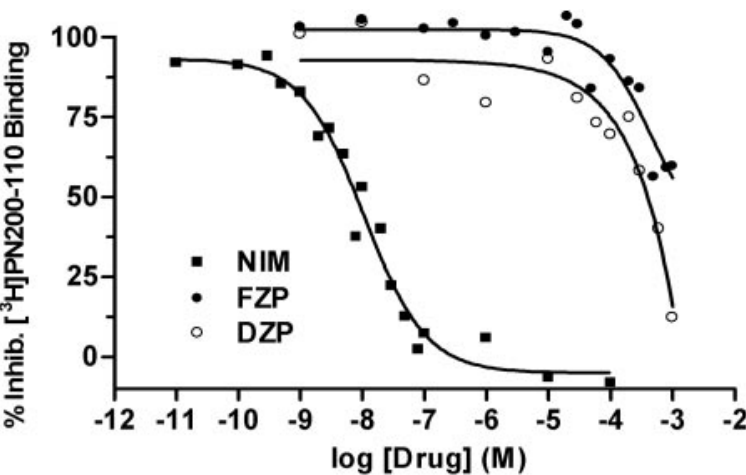

Fig. 5. Competitive inhibition of benzodiazepines at $\left[{ }^{3} \mathrm{H}\right]$ dihydropyridine binding sites. The benzodiazepines inhibited the binding of the highaffinity DHP PN200-110 to rat brain membranes with relatively low potency. In the absence of positive cations, both FZP (closed circles) and DZP (open circles) exhibited a concentration-dependent inhibition of specific $\left[{ }^{3} \mathrm{H}\right] \mathrm{PN} 200-110$ binding $\left(\mathrm{FZP} \mathrm{IC}_{50}=0.4 \mathrm{mM}\right.$; DZP $=1.3 \mathrm{mM}$ ). Nimodipine $\left(\mathrm{IC}_{50}=10.2 \mathrm{nM}\right.$; closed squares) displacement is shown for comparison.

tested. The benzodiazepine antagonist flumazenil $(1 \mu \mathrm{M})$ abolished $45.2 \pm 11.4 \%$ of the $\mathrm{Ca}^{2+}$ current, whereas coapplication of $1 \mu \mathrm{M}$ flumazenil and $1 \mu \mathrm{M}$ DZP inhibited $48.0 \pm$ $10.7 \%$ of the $\mathrm{Ca}^{2+}$ current, confirming that this inhibition is not mediated by action at the $\mathrm{GABA}_{\mathrm{A}}$ receptor benzodiazepine site.

Systemic Nimodipine Preinjection Prevents the Increase in AMPAR-Mediated mEPSCs in Neurons Isolated from 2-Day FZP-Withdrawn Rats. The time course of enhancement of $\mathrm{HVA} \mathrm{Ca}^{2+}$ current preceded and overlapped the window of AMPAR plasticity. To examine whether
Fig. 4. Voltage dependence of steady-state inactivation. A, inactivation pulse protocol: a $200-\mathrm{ms}$ test-pulse to $10 \mathrm{mV}$ was preceded by a 1.5-s conditioning prepulse. Voltage steps ranged from -80 to $10 \mathrm{mV}$ in $10-\mathrm{mV}$ increments. $V_{\mathrm{H}}$ was $-65 \mathrm{mV}$. B and $\mathrm{C}$, representative steady-state inactivation $\mathrm{Ca}^{2+}$ current traces from a control CA1 neuron (B) and a CA1 neuron isolated from a 2-day FZP-withdrawn rat (C). D, Boltzmann inactivation curves derived from individual fits of $\mathrm{Ca}^{2+}$ currents elicited from neurons isolated from control and FZP-withdrawn rats. There were no significant shifts in the inactivation curves from FZP-withdrawn neurons ( 0 day, open circles; 2 day, open squares) compared with their matched control neurons (0 day, closed circles; 2 day, closed squares). E, voltages of $V_{h}$ were not significantly different from that of FZP-withdrawn rats (0 day and 2 day, open bars) compared with their matched control rats ( 0 day and 2 day, solid bars). F, there were also no significant differences between the slopes $(d \mathrm{~V})$ of the inactivation curves between any FZP-withdrawn group (open bars) and their matched control group (solid bars). $\mathrm{mg} / \mathrm{kg}$ i.p. $)$ or vehicle $(0.5 \%$ Tween $80 ; 2 \mathrm{ml} / \mathrm{kg}$ i.p. $) 1$ day after FZP removal, and hippocampal slices were isolated 1 day later to evaluate AMPAR-mediated mEPSC characteristics. Figure 7A shows representative mEPSC current traces from neurons isolated from control rats or 2-day FZP-withdrawn rats injected with vehicle or nimodipine. Figure $7 \mathrm{~B}$ shows a rightward shift in the mean relative cumulative frequency plots of mEPSC amplitudes derived from CA1 neurons from FZP-withdrawn rats in comparison with matched controls injected with vehicle, at amplitudes ranging from 8 to $18 \mathrm{pA}$, plotted in 2-pA bins (ANOVA, $p<0.001$; Sheffé, $p<0.02$ ). Twenty-four hours after nimodipine injection, the distributions derived from FZP-withdrawn and control neurons overlapped. The average amplitudes of AMPAR-mediated mEPSCs $\left(V_{\mathrm{H}}=\right.$ $-80 \mathrm{mV}$ ) in CA1 neurons isolated from control and 2-day FZP-withdrawn rats were also compared. Figure $7 \mathrm{~B}$ and Table 2 show that prior vehicle injection again had no effect on basal AMPAR mEPSC amplitude in control neurons or on 

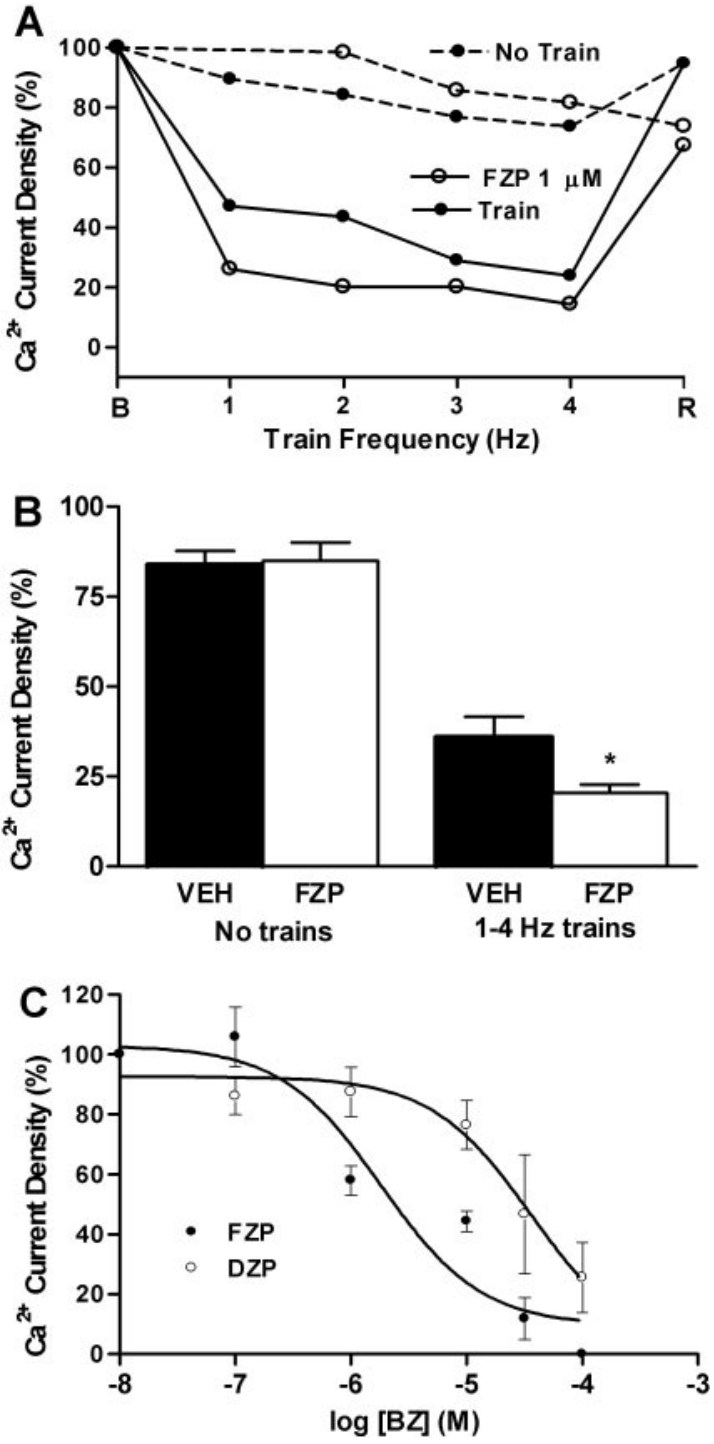

Fig. 6. Use- and concentration-dependent inhibition of $\mathrm{HVA} \mathrm{Ca}^{2+}$ current by benzodiazepines. The use- and concentration-dependent effect of benzodiazepines on $\mathrm{HVA} \mathrm{Ca}{ }^{2+}$ currents were evaluated in DIV 10 to 14 hippocampal cultured cells using whole-cell techniques. A, use-dependent effect of FZP on HVA $\mathrm{Ca}^{2+}$ currents. The $\mathrm{Ca}^{2+}$ current density was normalized and expressed as the percentage of the current evoked by baseline test pulse. Without a train of consecutive depolarizing pulses, 1 $\mu \mathrm{M}$ FZP showed little inhibitory effect on $\mathrm{HVA} \mathrm{Ca}^{2+}$ current. Following train application at frequencies of $1,2,3$, and $4 \mathrm{~Hz}$, preincubation with 1 $\mu$ M FZP resulted in approximately $45 \%$ inhibition by of $\mathrm{HVA} \mathrm{Ca}^{2+}$ current density compared with that in the presence of vehicle. Note the $\mathrm{Ca}^{2+}$-dependent inactivation of HVA $\mathrm{Ca}^{2+}$ current after trains of consecutive depolarizing pulses. A recovery test pulse (R), without prior train stimulation was given at the end of the recording to exclude run-down of $\mathrm{Ca}^{2+}$ channel function or seal degradation. $\mathrm{B}$, inhibition of $\mathrm{HVA} \mathrm{Ca}^{2+}$ current by FZP. FZP $(1 \mu \mathrm{M})$ had no effect on HVA $\mathrm{Ca}^{2+}$ currents in hippocampal cultured neurons in which depolarizing pulses were not applied (no trains: VEH, solid bar; FZP, open bar; $p>0.05$ ). In neurons in which consecutive depolarizing trains were applied, $1 \mu \mathrm{M}$ FZP inhibited had a similar effect to inhibit $\mathrm{HVA} \mathrm{Ca}^{2+}$ currents across all frequencies sampled; therefore, these data were averaged (1-4-Hz trains: VEH, $n=4$; FZP, $n=4 ; *, p<0.05$ ). C, concentration-dependent inhibition of HVA $\mathrm{Ca}^{2+}$ current by benzodiazepines. FZP and DZP $(0.1-100 \mu \mathrm{M})$ effects to inhibit $\mathrm{Ca}^{2+}$ current test pulses were evaluated after 5-min preincubation. $\mathrm{Ca}^{2+}$ current density was normalized and expressed as the percentage of the current evoked in the presence of vehicle.

mEPSC enhancement during FZP withdrawal. However, transient interruption of L-VGCC activity following acute systemic nimodipine administration to 1-day FZP-withdrawn rats was sufficient to restore mean AMPAR mEPSC amplitude to control levels in CA1 neurons from 2-day FZP-withdrawn rats. As reported previously (Van Sickle et al., 2004; Xiang and Tietz, 2007), there were no differences in neuronal resting membrane potential, mEPSC frequency, rise time, or current decay between neurons from control versus FZPwithdrawn rats.

\section{Discussion}

VGCCs play a major role in processes such as neurotransmitter release, synaptic plasticity, and gene expression (Catterall, 2000). The identified neuronal $\mathrm{HVA} \mathrm{Ca}^{2+}$ channel subfamilies (L-, N-, P/Q-, and R-types) have different voltage activation thresholds and different physiological functions (Catterall, 2000; Lipscombe et al., 2004). To evaluate their functional role in benzodiazepine dependence, the properties of HVA $\mathrm{Ca}^{2+}$ currents were investigated in CA1 pyramidal neurons acutely isolated from rat hippocampus following acute and prolonged benzodiazepine treatment using wholecell voltage-clamp techniques. HVA $\mathrm{Ca}^{2+}$ channel function developed in a time-dependent manner during prolonged benzodiazepine treatment and withdrawal (Fig. 2). A doubling of $\mathrm{HVA} \mathrm{Ca}^{2+}$ current density was detectable immediately after ending 1-week FZP administration and was sustained for at least 2 days after ending treatment before tapering off 3 days after treatment. Concomitant with the increase in $\mathrm{Ca}^{2+}$ current density, there was a negative shift in the voltage dependence of $\mathrm{Ca}^{2+}$ channel activation in 0-day and 2-day FZP-withdrawn rats (Fig. 3) without a change in the voltage dependence of steady-state inactivation (Fig. 4). The time course of enhancement of $\mathrm{HVA} \mathrm{Ca}^{2+}$ currents preceded and overlapped the transient increase in AMPAR-current potentiation, which was abolished by systemic nimodipine pretreatment. Collectively, the findings suggest that $\mathrm{Ca}^{2+}$ influx through L-VGCCs might contribute to the enhanced glutamatergic strength at CA1 neuron synapses associated with benzodiazepine withdrawal-anxiety (Van Sickle et al., 2004; Song et al., 2007; Xiang and Tietz, 2007).

Voltage-gated calcium channels have bee reported to play role in neuronal plasticity (Morgan and Teyler, 1999; Shinnick-Gallagher et al., 2003; Yasuda et al., 2003, Bloodgood and Sabatini, 2008). Thus, the increase in the HVA current amplitude could be mediated by a change in the relative contribution of one or more calcium channel subtypes. Using selective toxins from wasp and spider venoms, at least five functional subtypes of HVA channels, including L-, N-, P/Q-, and R-types have been identified, and functional investigations into their role in neuronal plasticity have been complicated by their presence on both presynaptic terminals and postsynaptic dendrites (Catterall, 2000; Bloodgood and Sabatini, 2008). Moreover, multiple classes of $\mathrm{Ca}^{2+}$ channels including low-activated T-types contribute to postsynaptic $\mathrm{Ca}^{2+}$ entry in spines (R, L, and $\mathrm{N}$ ) and dendrites (L and N) (Bloodgood and Sabatini, 2008). Both L- and R-type channels are involved in plasticity in CA1 neuron spines (Yasuda et al., 2003). Notwithstanding the range of possible $\mathrm{Ca}^{2+}$ channel subtypes that may be modulated in various models of activity-dependent plasticity, numerous investigations have suggested that disturbances of neuronal $\mathrm{Ca}^{2+}$ homeostasis, including enhanced $\mathrm{Ca}^{2+}$ entry associated with up-regula- 


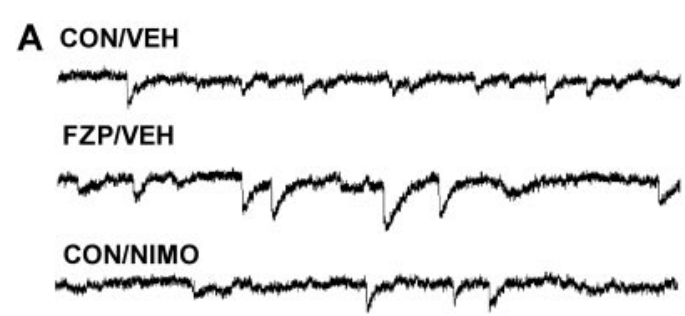

FZP/NIMO

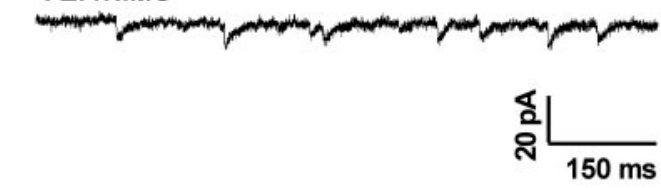

B
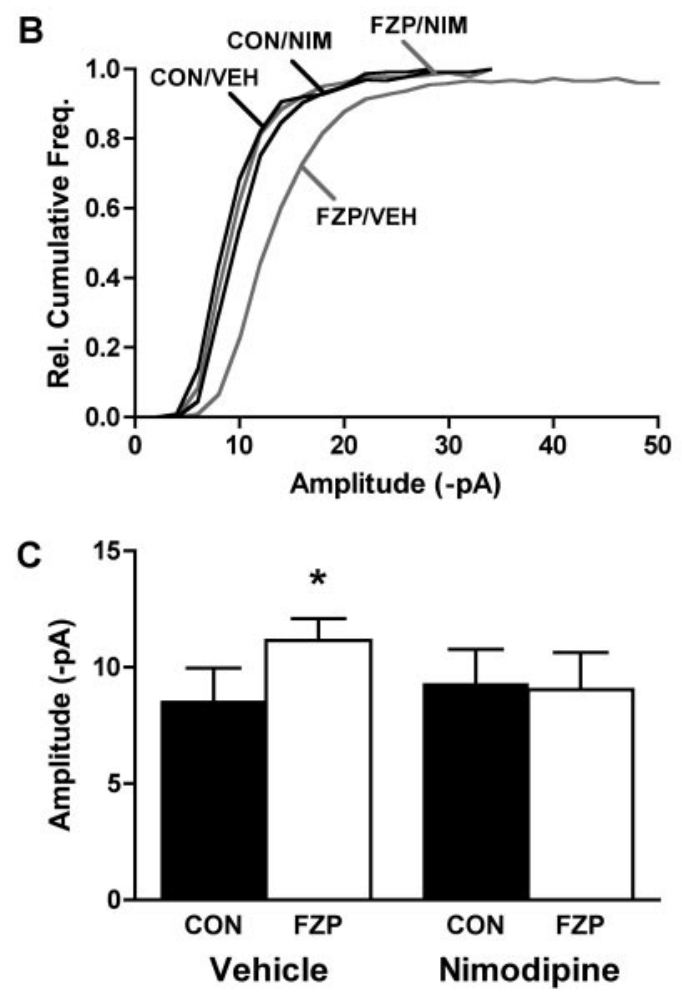

Fig. 7. Prior nimodipine injection prevents the increased in AMPARmediated mEPSCs in neurons isolated from 2-day FZP-withdrawn rats. Rats were injected systemically with the L-type VGCC antagonist nimodipine $(10 \mathrm{mg} / \mathrm{kg}$ i.p. $)$ or vehicle $(0.5 \%$ Tween $80 ; 2 \mathrm{ml} / \mathrm{kg}$ i.p. $) 1$ day after FZP removal. CA1 neurons were isolated from 2-day FZPwithdrawn rats the following day. A, representative mEPSC current traces in CA1 neurons from control rats $(\mathrm{CON})$ or 2-day FZP-withdrawn rats (FZP), injected with vehicle (VEH) or nimpodipine (NIM). $\mathrm{B}$, mean relative cumulative frequency plots of mEPSC amplitudes. There was a significant shift (ANOVA, $p<0.001$ ) in the amplitude distribution of mEPSCs in slices from 2-day FZP-withdrawn rats injected with vehicle (FZP/VEH, $n=8$; gray line) in comparison with control rats injected with vehicle (CON/VEH, $n=8$; black line), significant in comparisons of bins ranging from 8 to $18 \mathrm{pA}$ (Sheffé, $p<$ 0.02 ). Following nimodipine preinjection, the amplitude distributions overlapped (CON/NIM, $n=7$; black line; FZP/NIM, $n=5$; gray line). $\mathrm{C}$, average amplitudes of AMPAR-mediated mEPSCs $\left(V_{\mathrm{H}}=-80 \mathrm{mV}\right)$ in CA1 neurons isolated from control rats (solid bars) and 2-day FZP-withdrawn rats (open bars) were compared following either vehicle or nimodipine injection. As reported previously (Van Sickle et al., 2004) and illustrated in B, there was a significant increase in mEPSC amplitude $(39 \% ; p<0.05)$ in CA1 neurons from 2-day FZP-withdrawn rats $(n=8)$ in comparison with those isolated from control rats $(n=8)$. However, there was no difference in mEPSC amplitude in CA1 neurons from FZP-withdrawn rats $(n=5)$ given a systemic nimodipine injection $24 \mathrm{~h}$ before recording, compared with neurons isolated from the matched control group $(n=7)$ (also see Table 2). tion of L-type VGCC function, are involved in dependence on other central nervous system depressants such as ethanol, barbiturates, and morphine, as well as stimulants, including nicotine (Whittington and Little, 1993; Pourmotabbed et al., 1998; Rabbani and Little, 1999; Katsura et al., 2002). The finding that chronic, but not acute, benzodiazepine administration enhances $\mathrm{HVA} \mathrm{Ca}{ }^{2+}$ currents suggests that a similar effect may occur in hippocampal CA1 pyramidal neurons associated with benzodiazepine withdrawal symptoms (Van Sickle et al., 2004). Indeed, L-type calcium channel blockers such as nimodipine, nifedipine, and verapamil were reported to block a variety of benzodiazepine withdrawal signs (Gupta et al., 1996; El Ganouni et al., 2004). These studies raise the possibility of a potential role for L-VGCC activation in benzodiazepine dependence. Since a majority $(87.2 \% ; n=2)$ of the HVA $\mathrm{Ca}^{2+}$ current was blocked by $10 \mu \mathrm{M}$ nimodipine (Fig. 1B) and $75 \%$ by $40 \mu \mathrm{M}$ verapamil (data not shown), enhanced L-VGCC function probably contributes significantly to HVA current enhancement. However, a contribution from other HVA channels (N-, P/Q-, and R-type) cannot be excluded, and their roles in mediating benzodiazepine dependence remain to be elucidated.

Consistent with these findings, chronic benzodiazepine administration was reported to increase the number of DHPsensitive binding sites (Brennan and Littleton, 1991; Katsura et al., 2007). More recently, increased expression of L-VGCC subunits, including the $\alpha 1 \mathrm{C}\left(\mathrm{Ca}_{\mathrm{V}} 1.2 \alpha 1\right)$ and $\alpha 1 \mathrm{D}$ $\left(\mathrm{Ca}_{\mathrm{V}} 1.3 \alpha 1\right)$ subtypes, and associated $\alpha 2 / \delta 1$ subtypes, was demonstrated in vitro after chronic exposure to benzodiazepines. Increased subunit expression was also demonstrated in vivo in physically dependent mice (Katsura et al., 2007). In single CA1 neurons, increased $\mathrm{Ca}_{\mathrm{V}} 1.3 \alpha 1$ subunit transcript levels were positively correlated with increased VGCC activity (Chen et al., 2000). Because $\mathrm{Ca}_{\mathrm{V}} 1.3 \alpha 1$-containing channels activate at potentials approximately 20 to $25 \mathrm{mV}$ more hyperpolarized in comparison with $\mathrm{Ca}_{\mathrm{V}} 1.2 \alpha 1$-containing channels (Xu and Lipscombe, 2001; Lipscombe et al., 2004), an increase in $\mathrm{Ca}_{\mathrm{V}} 1.3 \alpha 1$ subunit protein in the $\mathrm{CA} 1$ region could explain both the increased current density and the negative shift in voltage dependence of $\mathrm{Ca}^{2+}$ current activation (Fig. 3). Yet, it is also known that $\mathrm{Ca}_{\mathrm{V}} 1.2 \alpha 1$-containing channels couple membrane depolarization to regulation of gene expression and to a variety $\mathrm{Ca}^{2+}$-mediated phosphorylation/dephosphorylation pathways that contribute to synaptic plasticity (Dolmetsch et al., 2001; Rajadhyaksha and Kosofsky, 2005). Therefore, modulation of the $\mathrm{Ca}_{\mathrm{V}} 1.2 \alpha 1$ subunit levels or phosphorylation state may also be involved in the HVA current enhancement. It will be of significant interest to investigate the expression of $\mathrm{Ca}_{\mathrm{V}} 1.2 \alpha 1$ and $\mathrm{Ca}_{\mathrm{V}} 1.3 \alpha 1$ subunit proteins in hippocampal CA1 region in FZP-withdrawn rats in relation to changes in L-VGCC single-channel function. Importantly, increased DHP-binding site number and increased expression of L-VGCC $\mathrm{Ca}_{\mathrm{V}} 1.2 \alpha 1$ and $\mathrm{Ca}_{\mathrm{V}} 1.3 \alpha 1$ subunits were also demonstrated in animals physically dependent on ethanol, morphine, or nicotine (Katsura et al., 2002, 2005; Hayashida et al., 2005; Shibasaki et al., 2007). Increases in expression of specific L-type channel subunits associated with enhanced $\mathrm{HVA} \mathrm{Ca}^{2+}$ channel function may provide a common mechanism underlying dependence on and addiction to a variety of drugs of abuse.

Although the precise mechanisms related to the negative shift in voltage dependence of $\mathrm{Ca}^{2+}$ current activation re- 
mains to be elucidated, this shift may have significant physiological importance following chronic benzodiazepine administration. As a consequence of prolonged $\mathrm{GABA}_{\mathrm{A}}$ receptor activation during FZP administration, numerous time-dependent changes occur at the $\mathrm{GABA}_{\mathrm{A}}$ receptor. Some of these changes may measurably influence CA1 neuron hyperexcitability (Van Sickle et al., 2004), including a bicarbonatedriven $\mathrm{Cl}^{-}$accumulation reflected in a shift in the $\mathrm{Cl}^{-}$reversal potential and the appearance of a bicuculline-sensitive depolarizing potential (Zeng et al., 1995; Zeng and Tietz, 1997, 1999). Lower threshold L-VGCCs, such as $\mathrm{Ca}_{\mathrm{V}} 1.3 \alpha 1-$ containing channels, would more likely be activated by these fast, subthreshold depolarizing driving forces and trigger $\mathrm{Ca}^{2+}$ influx. In fact, several studies have shown an increased accumulation of intracellular calcium through L-VGCCs following prolonged $\mathrm{GABA}_{\mathrm{A}}$ receptor activation that leads to bicarbonate-driven $\mathrm{Cl}^{-}$entry and $\mathrm{Cl}^{-}$accumulation (Reichling et al., 1994; Marty and Llano, 2005).

In addition to their well characterized effects at $\mathrm{GABA}_{\mathrm{A}}$ receptors, benzodiazepines were reported previously to inhibit neuronal VGCC-mediated $\mathrm{Ca}^{2+}$ flux (Taft and DeLorenzo, 1984; Reuveny et al., 1993; Ishizawa et al., 1997). Micromolar benzodiazepine binding sites were proposed to mediate benzodiazepine inhibition of depolarizationdependent $\mathrm{Ca}^{2+}$ uptake into synaptosomes, suggesting that diazepam brain concentrations achieved during intravenous administration for status epilepticus $(>10 \mu \mathrm{M})$ may be sufficient to block L-type VGCCs (Taft and DeLorenzo, 1984). Both FZP $\left(\mathrm{IC}_{50}=0.4 \mathrm{mM}\right)$ and DZP $\left(\mathrm{IC}_{50}=1.3 \mathrm{mM}\right)$ had weak potency to inhibit $\left[{ }^{3} \mathrm{H}\right] \mathrm{PN} 200-110$ binding to DHP binding sites (Fig. 5). Nonetheless, the potency of $\mathrm{FZP}\left(\mathrm{IC}_{50}\right.$ of $\sim 2$ $\mu \mathrm{M})$ and DZP $\left(\mathrm{IC}_{50}\right.$ of $\left.\sim 40 \mu \mathrm{M}\right)$ to inhibit $\mathrm{Ca}^{2+}$ channel currents in hippocampal cultures was significantly greater when $\mathrm{Ca}^{2+}$ channels were activated by a prior depolarizing train (Fig. 6), suggesting that benzodiazepine inhibition of VGCC-mediated currents is use-dependent, as shown previously with chlordiazepoxide (Reuveny et al., 1993). Oral flurazepam treatment of rats and other common diazepam treatment routes result in rat brain levels of benzodiazepine metabolites in the low micromolar range $(1.2 \mu \mathrm{M}$ flurazepam equivalents; $0.6 \mu \mathrm{M}$ in diazepam equivalents) (Xie and Tietz, 1992). Thus, the low micromolar benzodiazepine brain levels attained during chronic treatment would be expected to have their primary action on $\mathrm{GABA}_{\mathrm{A}}$ receptors but could also have prominent actions to interact with HVA channels. However, it is unlikely that the actions of the benzodiazepines to inhibit $\mathrm{Ca}^{2+}$ channels would result in up-regulation of L-VGCCs since chronic nimodipine reduces $\mathrm{Ca}_{\mathrm{V}} 1.3 \alpha 1$ subunit expression in hippocampus (Veng et al., 2003). Thus, it is possible that a secondary, opposing effect of the benzodiazepines to inhibit $\mathrm{Ca}^{2+}$ channels could lessen an effect of GABA depolarization to enhance L-VGCC expression. Alternately, the ability of benzodiazepines to inhibit $\mathrm{Ca}^{2+}$ channels during drug elimination from brain, up to 1 day after ending treatment $\left(t_{1 / 2}=<12 \mathrm{~h}\right)$ could contribute to the delay in the appearance of AMPAR potentiation and withdrawal symptoms.

Notably, the temporal pattern of modifications of HVA $\mathrm{Ca}^{2+}$ currents (Fig. $2 \mathrm{~F}$ ) preceded and overlapped the window of AMPAR synaptic plasticity, demonstrated previously to correlate with benzodiazepine withdrawal-anxiety in rats (Van Sickle et al., 2004; Xiang and Tietz, 2007). These find- ings suggest that $\mathrm{HVA} \mathrm{Ca}^{2+}$ channels, rather than $N$-methylD-aspartate receptors (Van Sickle et al., 2004), may serve as an important source of $\mathrm{Ca}^{2+}$-mediating hippocampal CA1 neuron hyperexcitability and synaptic plasticity associated with withdrawal-anxiety. Activation of neuronal $\mathrm{HVA} \mathrm{Ca}^{2+}$ channels triggers a transient influx of $\mathrm{Ca}^{2+}$ upon depolarization that, via diverse soluble messengers and transcription factors, initiates long-term processes related to synaptic plasticity in the hippocampus and amygdala (Dolmetsch et al., 2001). L-type VGCCs and N-methyl-D-aspartate receptors underlie two forms of long-term potentiation in hippocampal CA1 neurons in vivo (Morgan and Teyler, 1999). In midbrain striatal dopamine pathways, activation of L-VGCC calcium influx is proposed to activate downstream $\mathrm{Ca}^{2+} /$ calmodulinactivated kinase and phosphatase pathways, eventually involving cAMP response element-binding protein-induced gene expression, and psychostimulant-induced plasticity (Nestler, 2005; Rajadhyaksha and Kosofsky, 2005). The finding that prior systemic injection of the L-type VGCC antagonist nimodipine averted the up-regulation of CA1 neuron AMPAR function in 2-day FZP-withdrawn rats (Fig. 7), even after functional up-regulation of AMPARs in 1-day FZP-withdrawn rats, suggests that AMPAR regulation may be a dynamic process dependent on a sustained rise in intracellular $\mathrm{Ca}^{2+}$ during the FZP withdrawal period. The effect was not through a direct interaction between the antagonist and AMPARs, because nimodipine had no direct effect on AMPAR-mediated mEPSCs (Xiang and Tietz, 2007). These findings may also explain the ability of L-type calcium channel blockers to block a variety of benzodiazepine withdrawal signs, including hyperkinesia, hyperthermia, hyperaggression, and audiogenic seizures (Gupta et al., 1996; El Ganouni et al., 2004). The accumulated evidence supports the possibility that L-type VGCCs may be a major $\mathrm{Ca}^{2+}$ source for diverse intracellular messengers or transcription factors to increase glutamatergic strength during benzodiazepine withdrawal and contribute to benzodiazepine physical dependence.

Previous studies in FZP-withdrawn rats demonstrated that hippocampal CA1 neuron AMPAR-mediated hyperexcitability is an essential component of a functional anatomic circuit associated with expression of benzodiazepine withdrawal-anxiety (Xiang and Tietz, 2007). Coupled with the previous findings, the evidence provided in this report suggests that chronic benzodiazepine treatment and withdrawal enhances $\mathrm{HVA} \mathrm{Ca}^{2+}$ channel function in a transitory manner preceding the potentiation of AMPAR function and may be central to CA1 neuron AMPAR synaptic plasticity and benzodiazepine physical dependence. Altered L-type VGCCmediated $\mathrm{Ca}^{2+}$ homeostasis may also serve as a generalized mechanism for underlying physical dependence to a variety of drugs of abuse and may serve as a common site for pharmacological interventions to prevent withdrawal phenomena.

\section{Acknowledgments}

We thank Paromita Das, Krista Pettee, Brian Behrle, and William Ferencak, III, for expert contributions to this work.

\section{References}

Bloodgood BL and Sabatini BL (2008) Regulation of synaptic signaling by postsynaptic, non-glutamate receptor ion channels. J Physiol 586:1475-1480.

Brennan CH and Littleton JM (1991) Chronic exposure to anxiolytic drugs, working 
by different mechanisms causes upregulation of dihydropyridine binding sites on cultured bovine adrenal chromaffin cells. Neuropharmacology 30:199-205.

Budde T, Meuth S, and Pape HC (2002) Calcium-dependent inactivation of neuronal calcium channels. Nat Rev Neurosci 3:873-883.

Catterall WA (2000) Structure and regulation of voltage-gated calcium channels. Annu Rev Cell Dev Biol 16:521-555.

Chen KC, Blalock EM, Thibault O, Kaminker P, and Landfield PW (2000) Expression of alpha 1D subunit mRNA is correlated with L-type $\mathrm{Ca}^{2+}$ channel activity in single neurons of hippocampal "zipper" slices. Proc Natl Acad Sci U S A 97:43574362

Cui XY, Zhao X, Chu QP, Chen BQ, and Zhang YH (2007) Influence of diltiazem on the behavior of zolpidem-treated mice in the elevated-plus maze test. $J$ Neural Transm 114:155-160.

Dolmetsch RE, Pajvani U, Fife K, Spotts JM, and Greenberg ME (2001) Signaling to the nucleus by an L-type calcium channel-calmodulin complex through the MAP kinase pathway. Science 294:333-339.

El Ganouni S, Hanoun N, Boni C, Tazi A, Hakkou F, and Hamon M (2004) Prevention of diazepam withdrawal syndrome by nifedipine-behavioral and neurochem ical studies. Pharmacol Biochem Behav 79:269-277.

Gallager DW, Malcolm AB, Anderson SA, and Gonsalves SF (1985) Continuous release of diazepam: electrophysiological, biochemical and behavioral consequences. Brain Res 342:26-36.

Gershon E (1992) Effect of benzodiazepine ligands on $\mathrm{Ca}^{2+}$ channel currents in Xenopus oocytes injected with rat heart RNA. J Basic Clin Physiol Pharmacol 3:81-97.

Gorter JA, Borgdorff AJ, van Vliet EA, Lopes da Silva FH, and Wadman WJ (2002) Differential and long-lasting alterations of high-voltage activated calcium currents in CA1 and dentate granule neurons after status epilepticus. Eur J Neurosc 16:701-712.

Griffiths RR and Johnson MW (2005) Relative abuse liability of hypnotic drugs: a conceptual framework and algorithm for differentiating among compounds. J Clin Psychiatry 66:31-41.

Griffiths RR and Weerts EM (1997) Benzodiazepine self-administration in humans and laboratory animals-implications for problems of long-term use and abuse. Psychopharmacology (Berl) 134:1-37.

Gupta MB, Nath C, Patnaik GK, and Saxena RC (1996) Effect of calcium channel blockers on withdrawal syndrome of lorazepam in rats. Indian J Med Res 103: $310-314$

Hayashida S, Katsura M, Torigoe F, Tsujimura A, and Ohkuma S (2005) Increased expression of L-type high voltage-gated calcium channel alpha1 and alpha2/delta subunits in mouse brain after chronic nicotine administration. Brain Res Mo Brain Res 135:280-284.

Ishizawa Y, Furuya K, Yamagishi S, and Dohi S (1997) Non-GABAergic effects of midazolam, diazepam and flumazenil on voltage-dependent ion currents in NG108-15 cells. Neuroreport 8:2635-2638.

Katsura M, Mohri Y, Shuto K, Hai-Du Y, Amano T, Tsujimura A, Sasa M, and Ohkuma S (2002) Up-regulation of L-type voltage-dependent calcium channels after long-term exposure to nicotine in cerebral cortical neurons. J Biol Chem 277:7979-7988.

Katsura M, Torigoe F, Hayashida S, Honda T, Tsujimura A, and Ohkuma S (2005) Ethanol physical dependence is accompanied by up-regulated expression of L-type high voltage-gated calcium channel alpha1 subunits in mouse brain. Brain Res 1039:211-215

Katsura M, Shibasaki M, Kurokawa K, Tsujimura A, and Ohkuma S (2007) Upregulation of L-type high voltage-gated calcium channel subunits by sustained exposure to 1,4- and 1,5-benzodiazepines in cerebrocortical neurons. J Neurochem 103:2518-2528.

Lipscombe D, Helton TD, and Xu W (2004) L-type calcium channels: the low down. $J$ Neurophysiol 92:2633-2641.

Marty A and Llano I (2005) Excitatory effects of GABA in established brain networks. Trends Neurosci 28:284-289.

Morgan SL and Teyler TJ (1999) VDCCs and NMDARs underlie two forms of LTP in CA1 hippocampus in vivo. $J$ Neurophysiol 82:736-740.

Nestler EJ (2005) Is there a common molecular pathway for addiction? Nat Neurosci 8:1445-1449.

Peterson BZ and Catterall WA (1995) Calcium binding in the pore of L-type calcium channels modulates high affinity dihydropyridine binding. J Biol Chem 270 18201-18204.

Pourmotabbed A, Motamedi F, Fathollahi Y, Mansouri FA, and Semnanian S (1998) Involvement of NMDA receptors and voltage-dependent calcium channels on augmentation of long-term potentiation in hippocampal CA1 area of morphine dependent rats. Brain Res 804:125-134.

Rabbani M and Little HJ (1999) Increase in neuronal $\mathrm{Ca}^{2+}$ flux after withdrawal from chronic barbiturate treatment. Eur J Pharmacol 364:221-227.
Rajadhyaksha AM and Kosofsky BE (2005) Psychostimulants, L-type calcium channels, kinases, and phosphatases. Neuroscientist 11:494-502.

Reichling DB, Kyrozis A, Wang J, and MacDermott AB (1994) Mechanisms of GABA and glycine depolarization-induced calcium transients in rat dorsal horn neurons J Physiol 476:411-421.

Reuveny E, Twombly DA, and Narahashi T (1993) Chlordiazepoxide block of two types of calcium channels in neuroblastoma cells. J Pharmacol Exp Ther 264:2228

Sochivko D, Chen J, Becker A, and Beck H (2003) Blocker-resistant $\mathrm{Ca}^{2+}$ currents in rat CA1 hippocampal pyramidal neurons. Neuroscience 116:629-638.

Song J, Shen G, Greenfield LJ Jr, and Tietz EI (2007) Benzodiazepine withdrawalinduced glutamatergic plasticity involves up-regulation of GluR1-containing $\alpha$-amino-3-hydroxy-5-methylisoxazole-4-propionic acid receptors in hippocampal CA1 neurons. J Pharmacol Exp Ther 322:569-581.

Shibasaki M, Katsura M, Kurokawa K, Torigoe F, and Ohkuma S (2007) Regional differences of L-type high voltage-gated calcium channel subunit expression in the mouse brain after chronic morphine treatment. J Pharmacol Sci 105:177-183.

Shinnick-Gallagher P, McKernan MG, Xie J, and Zinebi F (2003) L-type voltagegated calcium channels are involved in the in vivo and in vitro expression of fear conditioning. Ann NY Acad Sci 985:135-149.

Taft WC and DeLorenzo RJ (1984) Micromolar-affinity benzodiazepine receptors regulate voltage-sensitive calcium channels in nerve terminal preparations. Proc Natl Acad Sci U S A 81:3118-3122.

Van Sickle BJ and Tietz EI (2002) Selective enhancement of AMPA receptormediated function in hippocampal CA1 neurons from chronic benzodiazepinetreated rats. Neuropharmacology 43:11-27.

Van Sickle BJ, Cox AS, Schak K, Greenfield LJ Jr, and Tietz EI (2002) Chronic benzodiazepine administration alters hippocampus CA1 neuron excitability: NMDA receptor function and expression. Neuropharmacology 43:595-606.

Van Sickle BJ, Xiang K, and Tietz EI (2004) Transient plasticity of hippocampus CA1 neuron glutamate receptors contributes to benzodiazepine withdrawal anxiety. Neuropsychopharmacology 29:1994-2006.

Veng LM, Mesches MH, and Browning MD (2003) Age-related working memory impairment is correlated with increases in the L-type calcium channel protein alpha1D (Cav1.3) in area CA1 of the hippocampus and both are ameliorated by chronic nimodipine treatment. Brain Res Mol Brain Res 110:193-202.

Walter HJ and Messing RO (1999) Regulation of neuronal voltage-gated calcium channels by ethanol. Neurochem Int 35:95-101.

Watson WP and Little HJ (2002) Selectivity of the protective effects of dihydropyridine calcium channel antagonist against the ethanol withdrawal syndrome. Brain Res 930:111-122.

Whittington MA and Little HJ (1993) Changes in voltage-operated calcium channels modify ethanol withdrawal hyperexcitability in mouse hippocampal slices. Exp Physiol 78:347-370.

Xiang K and Tietz EI (2007) Benzodiazepine-induced hippocampal CA1 neuron AMPA receptor plasticity linked to severity of withdrawal-anxiety: differential role of voltage-gated calcium channels and NMDA receptors. Behav Pharmacol 18: $447-460$.

Xie XH and Tietz EI (1992) Reduction in potency of selective $\gamma$-aminobutyric acid A agonist and diazepam in CA1 region of in vitro hippocampal slices from chronic flurazepam-treated rats. J Pharmacol Exp Ther 262:204-211.

$\mathrm{Xu}$ W and Lipscombe D (2001) Neuronal $\left.\mathrm{Ca}_{\mathrm{V}}\right) 1.3$ alpha(1) L-type channels activate at relatively hyperpolarized membrane potentials and are incompletely inhibited by dihydropyridines. $J$ Neurosci 21:5944-5951.

Yasuda R, Sabatini BL, and Svoboda K (2003) Plasticity of calcium channels in dendritic spines. Nat Neurosci 6:948-955.

Zeng X, Xie XH, and Tietz EI (1995) Reduction of GABA-mediated inhibitory postsynaptic potentials in hippocampus CA1 pyramidal neurons following oral flurazepam administration. Neuroscience 66:87-99.

Zeng X and Tietz EI (1997) Depression of early and late monosynaptic inhibitory postsynaptic potentials in hippocampal CA1 neurons following prolonged benzodiazepine administration: role of reduction in $\mathrm{Cl}^{-}$driving force. Synapse 25:125136.

Zeng XJ and Tietz EI (1999) Benzodiazepine tolerance at GABAergic synapses on hippocampal CA1 pyramidal cells. Synapse 31:263-277.

Address correspondence to: Dr. Elizabeth I. Tietz, Department of Physiol ogy and Pharmacology, University of Toledo College of Medicine (formerly Medical University of Ohio), University of Toledo Health Science Campus 3000 Arlington Ave., Mailstop 1008, Toledo, OH 43614. E-mail: liz.tietz@ utoledo.edu 